\title{
Urine and Fecal Microbiota in a Canine Model of Bladder
}

6 Ryan Mrofchak ${ }^{1}$, Christopher Madden ${ }^{1}$, Morgan V. Evans ${ }^{1,2}$, William C. Kisseberth, Deepika

7 Dhawan $^{3}$, Deborah W. Knapp ${ }^{3,4}$, and Vanessa L. Hale ${ }^{1^{*}}$

$9{ }^{1}$ Department of Veterinary Preventive Medicine, Ohio State University College of Veterinary

10 Medicine, Columbus, Ohio, United States of America

$11{ }^{2}$ Divison of Environmental Health Sciences, Ohio State University College of Public Health,

12 Columbus, Ohio, United States of America

$13{ }^{3}$ Department of Veterinary Clinical Sciences, Purdue University College of Veterinary Medicine,

14 West Lafayette, Indiana, United States of America

$15{ }^{4}$ Purdue University Center for Cancer Research, Purdue University, West Lafayette, Indiana,

16 United States of America

18 Conflicts of Interest: Ryan Mrofchak, Christopher Madden, Morgan V. Evans, William C.

19 Kisseberth, Deepika Dhawan, and Vanessa L. Hale have no conflicts of interest to report.

20 Deborah W. Knapp is an Editorial Board member of this journal, but was not involved in the

21 peer-review process nor had access to any information regarding its peer-review. 
23 *Corresponding Author:

24 Email: hale.502@ osu.edu

$25 \underline{\text { Abstract }}$

27 Introduction: Urothelial carcinoma (UC) is the tenth most diagnosed cancer in humans

28 worldwide. Dogs are a robust model for invasive UC as tumor development and progression is

29 similar in humans and dogs. Recent studies on urine microbiota in humans revealed alterations in

30 microbial diversity and composition in individuals with UC; however, the potential role of

31 microbiota in UC has yet to be elucidated. Dogs could be valuable models for this research, but

32 microbial alterations in dogs with UC have not been evaluated.

33 Objective: The objective of this this pilot study was to compare the urine and fecal microbiota

34 of dogs with UC ( $\mathrm{n}=7)$ and age-, sex-, and breed-matched healthy controls $(\mathrm{n}=7)$.

35 Methods: DNA was extracted from mid-stream free-catch urine and fecal samples using Qiagen

36 Bacteremia and PowerFecal kits, respectively. 16S rRNA gene sequencing was performed

37 followed by sequence processing and analyses (QIIME 2 and R).

38 Results: Canine urine and fecal samples were dominated by taxa similar to those found in

39 humans. Significantly decreased microbial diversity (Kruskal-Wallis: Shannon, $p=0.048$ ) and

40 altered bacterial composition were observed in the urine but not feces of dogs with UC

41 (PERMANOVA: Unweighted UniFrac, $p=0.011$ ). The relative abundances of Fusobacterium

42 was also increased, although not significantly, in the urine and feces of dogs with UC.

43 Conclusion: This study characterizes urine and fecal microbiota in dogs with UC, and it

44 provides a foundation for future work exploring host-microbe dynamics in UC carcinogenesis,

45 prognosis, and treatment. 
47 Key words: Bladder Cancer, Urine, Feces, Dogs, Gastrointestinal Microbiome, Microbiota, Pilot Study

$\underline{\text { 1. Introduction }}$

$50 \quad$ Bladder cancer is the tenth most diagnosed cancer worldwide [1]. In 2020, the International

51 Agency for Research on Cancer estimated over 573,000 new bladder cancer diagnoses would be

52 confirmed worldwide [2]. Urothelial carcinoma (UC), also known as transitional cell carcinoma,

53 is the most common type of bladder cancer. Age (being over age 55), race (white), sex (male),

54 and some heritable mutations [3-10] are established risk factors for bladder cancer [11-13].

55 Bladder cancer is also strongly associated with environmental exposures such as smoking [14-

56 17] or occupational exposure to chemicals like aromatic amines, pesticides, industrial dyes, or

57 diesel fumes $[18,19]$. However, not all persons exposed to these chemicals develop urothelial

58 carcinoma indicating that there are individualized host-environment interactions that mediate UC

59 risk.

60 Clear host-environment (diet) interactions mediated through the gut microbiome have

61 emerged in colorectal carcinogenesis [20,21] and environment-microbiome-carcinogenesis links

62 have also begun emerging in lung cancer [22,23]. For example, diets high in animal fat can

63 directly or indirectly impact microbial composition by increasing liver bile acid production and

64 excretion into the intestines. Bile tolerant microbes or microbes that can metabolize primary bile

65 acids expand in this bile-rich environment, and some of these microbes produce pro-

66 inflammatory, cytotoxic, or genotoxic secondary metabolites that can contribute to colorectal

67 carcinogenesis. Work on the gut microbiome has far outpaced and outnumbered studies on the

68 urine / bladder microbiome; however, it has now become apparent that the urine microbiota play

69 a key role in host health and may also be influencing bladder cancer development and 
70 progression [24]. Alterations in urine microbiota have been reported in association with multiple

71 genitourinary diseases including chronic kidney disease [25], chronic prostatitis, chronic pelvic

72 pain syndrome [26], interstitial cystitis [27], sexually transmitted infections [28], urgency urinary

73 incontinence [29], urinary tract infections [30], urinary stone disease [31], urogenital

74 schistosomiasis [32], urogynecologic surgery [33], and vaginosis [34]. A few recent studies on

75 the urine / bladder microbiome have also revealed subtle but intriguing differences in urine or

76 bladder tissue microbial diversity and composition of individuals with and without UC (Table 1)

$77 \quad[17,35-45]$, but approaches and results in these studies vary widely. Studies in relevant animal

78 models could advance this research by offering a more controlled environment. Multiple animal

79 models of UC have been described, with most being rodent models that have many limitations

80 [46].

81 The focus of this study was on invasive UC utilizing a naturally-occurring canine model and

82 comparing the urine and fecal microbiota of dogs with and without UC. While it can be difficult

83 to produce the collective features of cancer heterogeneity, molecular features, aggressive cancer

84 behavior, and host immunocompetence in experimental models, these features are present in the

85 canine model [57-59]. In humans, approximately $25 \%$ of all UC cases are muscle invasive [44]

86 while in dogs with UC, over $90 \%$ present with intermediate- to high-grade muscle invasive

87 bladder cancer $[47,48]$. Moreover, humans and dogs share many of the same environmental

88 exposures, and canine UC, like human UC, has been epidemiologically linked to chemical

89 exposures including herbicides and pesticides [49,50]. Dogs also exhibit strong heritable (breed-

90 specific) associations with UC offering unique opportunities for gene-environment studies [49-

$9151]$. Notably, the human microbiome is more similar to the dog microbiome compared to other 
92 animal models, such as the rodent microbiome [52], making dogs a more suitable model for

93 studying microbiota in relation to UC.

94

$95 \quad$ 2. Materials and Methods

96 2.1 Sample Collection: All dogs were recruited through Purdue University College of

97 Veterinary Medicine between September 2016 and October 2019 (Purdue IACUC: 1111000169;

98 Ohio State University IACUC: 2019A00000005). Urine and fecal samples were initially

99 collected from 57 dogs with biopsy-confirmed urothelial carcinoma (UC) and 56 age, sex, and

100 breed-matched healthy controls (Figure 1). Dogs with active urinary tract infections were

101 excluded. We additionally excluded any dog with a history of chemotherapy (vinblastine,

102 zebularine, vemurafenib, chlorambucil, mitoxantrone, and cyclophosphamide) or a history of

103 antibiotics within the previous 3 weeks due to the potential effects of these medications on the

104 microbiome [53-60]. We did not exclude dogs on non-steroidal anti-inflammatory drugs

105 (NSAIDs), including piroxicam and deracoxib, which are commonly used in dogs with UC.

106 Healthy dogs underwent physical exams and had no history of antibiotics (within the previous 3

107 weeks) or indications of gastrointestinal or urogenital disease.

108 In healthy dogs, urine was collected via mid-stream free catch. In dogs with UC, a variety

109 of urine collection methods were employed as deemed clinically appropriate including: mid-

110 stream free catch, catheter, or cystoscopy. Free catch urine can include bacteria from the bladder,

111 urethra, periurethral skin, prepuce, or vagina, while urine collected via catheterization or

112 cystoscopy primarily includes microbes from the bladder and limits the presence of genital and

113 skin microbes [41,61-63]. To determine if collection method could potentially influence our

114 results, we compared samples from dogs with UC collected via free catch $(\mathrm{n}=8)$ to samples 
115 collected via non-free catch methods (catheterization, cystoscopy) $(\mathrm{n}=11)$ (Supp. Table 1;

116 Supp. Figures 1,2,3). We observed significant differences in microbial composition but not

117 diversity by collection method (Bray-Curtis PERMANOVA rarefied: $p=0.008$; non-rarefied: $p$

$118=0.005$; Supp. Figures, 1f,2f). Moreover, Staphylococcus and Streptococcus - common skin

119 colonizers - were amongst the top genera in free catch urine but not amongst the top genera in

120 non-free catch urine (Supp. Table 2). Based on the compositional differences we observed by

121 collection method and on other studies that have reported differences in urine microbiota due to

122 collection method [41,61-65], we opted to limit the remainder of our analyses to samples

123 collected via free catch only. This allowed us to compare microbiota in urine from healthy dogs

124 and dogs with UC without introducing collection method as a potential confounder.

125 As such, after exclusions, urine samples from a total 7 dogs with UC and 7 age, sex, and

126 breed-matched healthy controls were compared in this study (Table 2). Fecal microbiota from a

127 subset of these 14 dogs for which we had fecal samples (4 dogs with UC and 6 healthy controls)

128 were also compared [30,66,67]. All urine and stool samples were placed on ice immediately after

129 collection and then transferred into a $-80^{\circ} \mathrm{C}$ freezer. Samples were transported on dry ice from

130 Purdue (West Lafayette, IN, USA) to the Ohio State University (Columbus, OH, USA), where

131 they were stored in at $-80^{\circ} \mathrm{C}$ until extraction.

$133 \quad$ 2.2 DNA extraction and quantification: Urine samples were extracted using QIAamp ${ }^{\circledR}$

134 BiOstic ${ }^{\circledR}$ Bacteremia DNA Isolation Kit (Qiagen, Hilden, Germany) as described previously

135 [68]. Fecal samples were extracted using the QIAamp ${ }^{\circledR}$ PowerFecal $^{\circledR}$ DNA Kit (Qiagen, Hilden,

136 Germany) following the manufacturer's instructions. Negative (no sample) controls were run

137 with each kit used for extraction. DNA concentrations were measured using a Qubit ${ }^{\circledR} 4.0$ 
138 Fluorometer (Invitrogen, Thermo Fisher Scientific ${ }^{\mathrm{TM}}$, Carlsbad, CA, USA) and purity was

139 assessed using Nanodrop One (Thermo Fisher Scientific ${ }^{\mathrm{TM}}$, Carlsbad, CA, USA).

$141 \quad 2.316 S$ rRNA sequencing and sequence processing: Library preparation, PCR amplification,

142 and amplicon sequencing was performed at Argonne National Laboratory (DuPage County,

143 Illinois). Likewise, negative controls underwent the full extraction, library preparation, and

144 sequencing process. We amplified the V4 region of the $16 \mathrm{~S}$ rRNA gene using primers 515F and

145 806R, and PCR and sequencing were performed as described previously (2 x 250bp paired-end

146 reads, on an Illumina Miseq (Lemont, IL, USA)) [68-70]. Raw, paired-end sequence reads were

147 processed using QIIME2 v. 2020.11 and DADA2 [71,72]. Taxonomy was assigned in QIIME2

148 using the Silva $13299 \%$ database and the 515F / 806R classifier [73,74]. In the analysis

149 comparing urine collection method in dogs with UC, we excluded samples with fewer than 1,000

150 reads and analyzed the data with rarefaction (at 1,000 reads) and without rarefaction. We

151 included both analyses because rarefaction, especially at low read counts, can increase type 1

152 errors and mask potential differentially abundant taxa between samples [75]. In the analyses

153 comparing urine and fecal microbiota from dogs with and without UC, samples with fewer than

1547,000 reads were excluded; this cutoff allowed us to retain all but two urine samples while

155 excluding all negative controls (Figure 1). Urine samples from dogs with and without UC were

156 rarefied at 7,000 reads; fecal samples were rarefied at 9,233 reads, which included all fecal

157 samples. Sequencing data for this project is available in SRA BioProject PRJNA76392.

1592.4 Urine and fecal sequence data processing: Prior to analyses, we first removed singletons

160 (Amplicon Sequence Variants (ASVs) with only one read in the dataset). ASVs are roughly 
161 equivalent to a microbial species or strain. We then applied the R package decontam to identify

162 and filter out putative contaminant ASVs based on their frequency and prevalence (0.5 threshold)

163 as compared to negative controls (R package, v.1.10.0) [76]. In total, we identified and removed

16413 putative contaminant ASVs from the urine samples and 8 from the fecal samples (Supp.

165 Table 3). We also removed sequences aligned to chloroplasts, eukaryotes, mammalia, and

166 mitochondria. In addition, in the urine samples, we removed taxa within the phylum

167 Cyanobacteria and the class Chloroflexia. All six negative controls, which contained fewer than

1687000 reads, were then removed from subsequent analyses.

169

170 2.5. Statistical analyses: Data were tested for normality using the Shapiro Wilk Normality Test

171 in R version 3.5.2 [77]. We then compared DNA concentrations and read numbers between

172 groups using Wilcoxon Rank Sum tests and two-sample t-tests, respectively. All alpha and beta

173 diversity metrics were assessed using the R package phyloseq with a p-value cutoff of 0.05

174 adjusted using the Benjamini \& Hochberg False Discovery Rates [78]. Alpha-diversity metrics

175 included Shannon, Simpson, and Observed Features followed by Kruskal-Wallis Rank Sum

176 Tests to compare metrics by group. Beta-diversity metrics included Bray-Curtis, Unweighted

177 UniFrac, and Weighted UniFrac. Permutational Multivariate Analysis of Variance

178 (PERMANOVA) were implemented in QIIME2 v. 2020.11 to compare bacterial community

179 composition by group. An Analysis of Composition of Microbiome (ANCOM) was used to

180 identify differentially abundant taxa by group.

181

182 3. Results 
3.1 Urine microbiota in dogs with UC: We compared the urine microbiota of 7 dogs with UC

184 to 7 age, sex, and breed-matched healthy controls. The total number of reads across all samples

185 ranged from 7,232 - 36,692 with a mean of 20,010 \pm 7,329 reads. Urine samples contained a

186 total of 21 bacterial phyla, 308 genera, and 187 species. Urine DNA concentrations were

187 significantly higher in dogs with UC as compared to healthy dogs (Figure 2a: Wilcoxon Rank

188 Sum test, $p=0.002$ ), but there was no significant difference in the number of $16 \mathrm{~S}$ reads between

189 dogs with and without UC (Figure 2b: two-sample t-test, $p=0.99$ ).

Dogs with UC had significantly lower urine microbial diversity compared to healthy dogs

191 as measured by the Shannon diversity index and Observed Features but not by the Simpson

192 diversity index (Kruskal-Wallis: Shannon, $p=0.048$; Observed Features, $p=0.025$; Simpson, $p$

$193=0.133$; Figure 3a, Supp. Figure 4a,b). Dogs with UC also had significantly different urine

194 microbial composition than healthy dogs based on an Unweighted UniFrac distance matrix

195 (Figure 3b; PERMANOVA, $p=0.011$ ); although, no significant differences were observed by

196 Bray Curtis $(p=0.888)$ or Weighted UniFrac $(p=0.168)$ distance matrices (Supp. Figure 4c,d).

197 At the phylum level, Firmicutes (healthy: 61.1\%; UC: $79.5 \%$ ) Proteobacteria (healthy: $18.0 \%$;

198 UC: $15.6 \%$ ), and Actinobacteria (healthy: $12.5 \%$; UC: $4.26 \%$ ) were the three most abundant

199 phyla in the urine of healthy dogs and dogs with UC (Figure 4a). At the family level,

200 Staphylococcaceae (healthy 42.6\%; UC 48.6\%) and Streptococcaceae (healthy $5.99 \%$; UC

201 14.8\%) were amongst the most abundant taxa (Figure 4b; For genus and order level taxa see

202 Supp. Figure 5). Interestingly, Fusobacterium was present in the urine of dogs with UC but not

203 in the urine of healthy dogs (relative abundance of Fusobacterium in healthy dogs: $0 \%$; in dogs

204 with UC: $0.167 \%$ ). There were no differentially abundant taxa between healthy dogs and dogs

205 with UC at the phylum, genus, or ASV levels. 
3.2 Fecal microbiota in dogs with UC: We compared the fecal microbiota of a subset of dogs from the urine analyses for which we also had fecal samples: four dogs with and six dogs without UC. The total number of reads across all fecal samples ranged from 9,233 - 28,345 with a mean of $19,196 \pm 6,100$ reads. Fecal samples contained a total of 8 bacterial phyla, 92 genera,

211 and 45 species. There was no significant difference in fecal DNA concentrations or number of

$21216 \mathrm{~S}$ reads in dogs with UC as compared to healthy dogs; although, DNA concentrations were

213 greater in dogs with UC (DNA concentration: Wilcoxon Rank Sum Test, $p=0.136$; $16 \mathrm{~S}$ reads:

214 Two-sample t-test, $p=0.322$; Figure 5).

215 Fecal microbial diversity and composition did not differ significantly in dogs with and 216 without UC (Kruskal-Wallis: Shannon, $p=0.67$; Unweighted UniFrac PERMANOVA, $p=$

217 0.252; Figure 6, Supp. Figure 6). The top three most abundant phyla across all fecal samples

218 were Firmicutes (healthy: $72.6 \%$; UC: $32.9 \%$ ), Bacteroidetes (healthy: 10.6 \%, UC $31.9 \%$ ) and

219 Fusobacteria (healthy: $11.3 \%$, UC: $31.1 \%$ ) (Figure 7; Supp. Figure 7). At the family and

220 genera levels, Fusobacterieacea (healthy: $11.4 \%$, UC: $31.7 \%$ ) and Fusobacterium (healthy: 12.0

$221 \%$, UC: $33.1 \%$ ) were the most abundant taxa in UC but not healthy samples, respectively;

222 although, these differences were not statistically significant. Only one Bacteroides spp. was

223 significantly increased in relative abundance in dogs with UC compared to healthy dogs

224 (ANCOM, $\mathrm{W}=25)$.

225 To determine how results from this subset of fecal samples compared to a larger sample 226 set, we then analyzed the fecal microbiota of 30 dogs with UC and 30 sex, age, and breed-

227 matched healthy controls (Supp. Table 4). Fecal DNA concentrations, 16S reads, and fecal 228 microbial diversity and microbial composition again did not differ significantly between groups 
229 (DNA concentration: Wilcoxon Rank Sum test, $p=0.515 ; 16 \mathrm{~S}$ reads: two-sample $\mathrm{t}$-test, $p=$

230 0.0697; Supp. Figure 8; Supp. Table 5). Firmicutes, Bacteroidetes, and Fusobacteria also

231 remained the most abundant phyla across both groups, and interestingly, Fusobacteriaceae

232 (healthy: 17.4\%; UC: $28 \%$ ) and Fusobacterium (healthy: 18.5\%; UC: 29.2\%) were still the

233 most abundant family and genus in the fecal samples of dogs with UC (Supp. Figure 9);

234 although, this difference was still not significant. In fact, no taxa were differentially abundant at

235 the phylum, genus, or ASV levels between groups in the larger sample set (Supp. Table 5),

236 suggesting that that Bacteroides spp. identified as differentially abundant in the subset was likely

237 an artifact of small sample size.

239 3.3 Microbiota identified in both fecal and urine samples: As the gut can be a source for

240 microbes in the urinary tract [30,67], we then combined urine and fecal data to determine what

241 ASVs were present in both urine and fecal samples. There were a total of 1,204 ASVs across all

242 urine and fecal samples combined. Sixty-six ASVs were identified in both urine and fecal

243 samples from any dog (Supp. Table 6). The most common taxa found in both urine and fecal

244 samples included taxa in the genera Streptococcus and Blautia. Notably, Fusobacterium spp.,

245 Porphyromonas spp., Campylobacter spp., Helicobacter spp., and Clostridiodes difficile were

246 also found in both urine and fecal samples. Further, nine ASVs were identified in urine and fecal

247 samples from the same dogs (Supp. Table 7). These ASVs included two Escherichia or Shigella

248 spp., two Streptococcus spp., a Clostridium sensu stricto 1 spp., Actinomyces coleocanis,

249 Streptococcus minor, an Enterococcus spp., and an uncultured Peptoclostridium spp. 
252 The purpose of our study was to characterize the urine and fecal microbiota in a naturally-

253 occurring canine model of UC. We report a decreased urine microbial diversity and altered urine

254 microbial composition in dogs with UC compared to healthy controls. We did not detect

255 significant differences in fecal microbiota between dogs with and without UC; although,

256 Fusobacterium was increased in dogs with UC. These results provide a foundation for further

257 exploring the role of microbes in UC in a highly relevant animal model.

\section{Urine and fecal microbiota associated with UC}

260 The higher concentrations of DNA found in urine from dogs with UC is likely host DNA from

261 epithelial or tumor cells being sloughed into the urine. Notably, urine microbial read numbers did

262 not differ significantly between dogs with and without UC indicating similar amplicon

263 sequencing depths despite differences in DNA concentrations. (Notably, efforts to remove host

264 DNA from UC urine samples prior to sequencing may be beneficial in future microbiome studies

265 employing shotgun metagenomics to ensure that the run is not overwhelmed with host

266 sequences.)

267 Besides DNA concentrations, we also observed significant differences in urine microbial

268 diversity (Shannon) and composition (Unweighted UniFrac) between dogs with and without UC.

269 In this study, urine microbial diversity was greater in healthy dogs as compared to dogs with UC,

270 a finding that aligns with several studies on urine microbiota in humans with UC [37,39].

271 However, there are also studies in humans that report no differences in microbial diversity or

272 decreased diversity in urine from healthy individuals as compared to those with UC

$273[17,35,36,38,42,44,79]$. Differences in microbial composition (Unweighted UniFrac) have also

274 been reported in previous human studies on UC $[36,38,43,44]$. In this study, the four most 
275 abundant phyla in urine were Firmicutes, Actinobacteria, Bacteroides, and Proteobacteria. These

276 phyla also dominate the urine microbiota in humans [17,36,38,40,44,45] and have been reported

277 in previous studies on healthy dog urine [80,81]. In humans, taxa associated with UC vary

278 widely across studies, but Acinetobacter and Actinomyces have been found at increased

279 abundances in patients with UC across at least three studies $[35,42,44]$. In this study, we did not

280 see Acinetobacter or Actinomyces spp. increased in relation to UC, which may be due to small

281 sample sizes and reduced power to detect differentially abundant taxa, or differences between

282 human and canine urine microbiota, or lack of a true link between these taxa and UC.

283 In relation to fecal microbiota, we did not observe any significant differences in dogs

284 with and without UC. However, intriguingly, Fusobacterium was increased in relative abundance

285 (although not significantly) in urine and fecal samples of dogs with UC. One previous study on

286 bladder cancer also reported increased Fusobacterium in the urine of individuals (human) with

287 UC [38]. Importantly, taxa in the phyla Fusobacteria are considered normal inhabitants of the

288 canine gastrointestinal tract [82]; although, they are more typically associated with disease in

289 humans. Studies in colorectal cancer have demonstrated direct links between Fusobacteria

290 (Fusobacterium nucleatum) and carcinogenesis. Specifically, Fusobacterium nucleatum Fap2

291 protein can bind to host factor Gal-GalNAc which is overexpressed on tumor cells [83] - thereby

292 localizing to tumors where Fap2 can impair host anti-tumor immunity [83]. Fusobacterium

293 nucleatum can also induce the host Wnt / beta-catenin pathway resulting in upregulated host

294 cellular proliferation [84]. Future studies are needed to elucidate the potential role of

295 Fusobacterium in bladder cancer.

297 Microbiota present in both urine and fecal samples 
298 Communication and migration of microbes between the gut and bladder can increase a host's

299 risk of UTIs and bacteriuria [30]. Microbes may migrate and ascend into the urogenital tract

300 externally from the rectum / anus, or internally via the blood stream [85,86]. In this study, 66

301 ASVs were shared between urine and fecal samples. Interestingly, $59 \%$ of those ASVs (39 /

302 66) are likely spore-formers (Bacilli, Clostridia, Negativicutes) suggesting that spore formation

303 may more readily enable exchange of microbes between body niches $[87,88]$. Among the

304 microbes (ASVs) found in both urine and fecal samples, there were multiple potentially

305 pathogenic taxa: Campylobacter spp., Helicobacter canis, Clostridiodes difficile, Clostridium

306 baratii, Escherichia / Shigella spp., and Enterococcus spp. There were also a few taxa that have

307 been associated with tumors or directly linked with tumor development or progression in

308 gastrointestinal, oral, and genital cancers: Fusobacterium spp. and Porphyromonas spp. [89-94].

309 The shared presence of two Fusobacterium ASVs between urine and fecal samples is particularly

310 of interest given the role of Fusobacterium in colorectal cancer.

311 This pilot study is a novel investigation of urine and fecal microbiota in a canine model

312 of UC. The dominant microbial taxa identified in canine urine and fecal samples were similar to

313 those reported in humans. Also, as in humans, altered microbial diversity and composition were

314 observed in dogs with UC as compared to healthy controls. This supports the idea that the

315 microbiota may play a role in UC development, progression, prognosis, or response to treatment,

316 as has been observed in other cancers. Moreover, Fusobacterium was increased - albeit not

317 significantly - in both urine and fecal samples of dogs with UC. Fusobacterium ASVs were also

318 shared between urine and fecal samples. Taken together, these results provide support for the use

319 of dogs as a model in UC microbiome studies. Additionally, these findings suggest that future 
320 work evaluating the role of Fusobacterium in UC, and the gut as a potential source of this

$321 \quad$ Fusobacterium, may be warranted.

322

323 Funding and Acknowledgements:

324 We are grateful to all individuals involved in sample collection at Purdue University

325 College of Veterinary Medicine (West Lafayette, IN, USA) and to the dogs and dog owners who

326 participated in this study. We also acknowledge the Ohio Supercomputer Center (Columbus,

327 Ohio, USA, established 1987) for computing resources used in this study.

328 Funding for this project was provided by the Ohio State University College of Veterinary

329 Medicine Department of Veterinary Preventive Medicine (VLH, RM, CM), the Ohio State

330 University Infectious Diseases Institute (VLH, RM, CM), the Ohio State University College of

331 Veterinary Medicine Canine Funds (VLH, WK, DK), and the Ohio State University College of

332 Public Health Collaborative Postdoctoral Research Program Award (MVE).

334 Author Contributions:

335 Conceptualization: Vanessa L. Hale, Deborah W. Knapp, and William C. Kisseberth

336 Clinical sample collection, clinical care / monitoring, clinical data extraction: Deborah W.

337 Knapp, Deepika Dhawan, and William C. Kisseberth

338 DNA extraction: Chris Madden, Ryan Mrofchak, and Morgan V. Evans

339 Data processing, analysis: Ryan Mrofchak, Morgan, V. Evans, Chris Madden, and Deborah W.

340 Knapp

341 Data interpretation and conclusions: Ryan Mrofchak, Vanessa L. Hale, Chris Madden, and

342 Deborah W. Knapp 
bioRxiv preprint doi: https://doi.org/10.1101/2021.12.20 472715; this version posted December 21, 2021. The copyright holder for this preprint (which was not certified by peer review) is the author/funder, who has granted bioRxiv a license to display the preprint in perpetuity. It is made available under aCC-BY 4.0 International license.

343 Manuscript writing: Ryan Mrofchak, Vanessa L. Hale, and Chris Madden

344 Manuscript editing: Chris Madden, Deepika Dhawan, Deborah W. Knapp, and William C.

345 Kisseberth

346 
1. World Bladder Cancer Patient Coalition. GLOBOCAN 2020: Bladder cancer 10th most common diagnosed worldwide [Internet]. Lyon, France; 2020. Available from: https://worldbladdercancer.org/news_events/globocan-2020-bladder-cancer-10th-mostcommonly-diagnosed-worldwide/

2. Sung H, Ferlay J, Siegel RL, Laversanne M, Soerjomataram I, Jemal A, et al. Global Cancer Statistics 2020: GLOBOCAN Estimates of Incidence and Mortality Worldwide for 36 Cancers in 185 Countries. CA Cancer J Clin. 2021 May 4;71(3):209-49. Available from: https://onlinelibrary.wiley.com/doi/10.3322/caac.21660

3. Randi G, Pelucchi C, Negri E, Talamini R, Galeone C, Franceschi S, et al. Family history of urogenital cancers in patients with bladder, renal cell and prostate cancers. Int J Cancer. 2007 Dec 15;121(12):2748-52. Available from: http://doi.wiley.com/10.1002/ijc.23037

5. Murta-Nascimento C, Silverman DT, Kogevinas M, García-Closas M, Rothman N, 
371 7. Chu H, Wang M, Zhang Z. Bladder cancer epidemiology and genetic susceptibility. J

372 Biomed Res. 2013 May 30;27(3):170-8. Available from: http://www.jbr-

373 pub.org.cn/en/article/doi/10.7555/JBR.27.20130026

374 8. Mucci LA, Hjelmborg JB, Harris JR, Czene K, Havelick DJ, Scheike T, et al. Familial

375 Risk and Heritability of Cancer Among Twins in Nordic Countries. JAMA. 2016 Jan

$376 \quad 5 ; 315(1): 68$. Available from:

377 http://jama.jamanetwork.com/article.aspx?doi=10.1001/jama.2015.17703

378 9. Martin C, Leiser CL, O’Neil B, Gupta S, Lowrance WT, Kohlmann W, et al. Familial

379 Cancer Clustering in Urothelial Cancer: A Population-Based Case-Control Study. JNCI J

380 Natl Cancer Inst. 2018 May 1;110(5):527-33. Available from:

$381 \quad$ https://academic.oup.com/jnci/article/110/5/527/4698132

382 10. Aveyard JS, Skilleter A, Habuchi T, Knowles MA. Somatic mutation of PTEN in bladder carcinoma. Br J Cancer. 1999 May 23;80(5-6):904-8. Available from: http://www.nature.com/articles/6690439

385 11. Antoni S, Ferlay J, Soerjomataram I, Znaor A, Jemal A, Bray F. Bladder Cancer Incidence 386 and Mortality: A Global Overview and Recent Trends. Eur Urol. 2017 Jan;71(1):96-108.

387 Available from: https://linkinghub.elsevier.com/retrieve/pii/S0302283816302809

388 12. American Cancer Society. Key Statistics for Bladder Cancer [Internet]. 2021. Available from: https://www.cancer.org/cancer/bladder-cancer/about/key-statistics.html

390 13. Wang Y, Chang Q, Li Y. Racial differences in Urinary Bladder Cancer in the United 391 States. Sci Rep. 2018 Dec 21;8(1):12521. Available from:

392 http://www.nature.com/articles/s41598-018-29987-2

393 14. Cumberbatch MG, Rota M, Catto JWF, La Vecchia C. The Role of Tobacco Smoke in 
Bladder and Kidney Carcinogenesis: A Comparison of Exposures and Meta-analysis of

Incidence and Mortality Risks. Eur Urol. 2016 Sep;70(3):458-66. Available from:

15. Alguacil J, Kogevinas M, Silverman DT, Malats N, Real FX, García-Closas M, et al.

Jun;32(6):843-7. Available from: https://academic.oup.com/carcin/article-

16. Burger M, Catto JWF, Dalbagni G, Grossman HB, Herr H, Karakiewicz P, et al. Epidemiology and Risk Factors of Urothelial Bladder Cancer. Eur Urol. 2013 2018 May 31;8(167). Available from:

18. Pesch B, Taeger D, Johnen G, Gawrych K, Bonberg N, Schwentner C, et al. Screening for bladder cancer with urinary tumor markers in chemical workers with exposure to aromatic amines. Int Arch Occup Environ Health. 2014 Oct 16;87(7):715-24. Available from:

413 19. Koutros S, Silverman DT, Alavanja MC, Andreotti G, Lerro CC, Heltshe S, et al. 
417 20. O'Keefe SJD. Diet, microorganisms and their metabolites, and colon cancer. Nat Rev

418 Gastroenterol Hepatol. 2016 Dec 16;13(12):691-706. Available from:

419 http://www.nature.com/articles/nrgastro.2016.165

420 21. Sears CL, Garrett WS. Microbes, Microbiota, and Colon Cancer. Cell Host Microbe. 2014

421 Mar;15(3):317-28. Available from:

422 https://linkinghub.elsevier.com/retrieve/pii/S1931312814000651

423 22. Mao Q, Jiang F, Yin R, Wang J, Xia W, Dong G, et al. Interplay between the lung

424 microbiome and lung cancer. Cancer Lett. 2018 Feb;415:40-8. Available from:

425 https://linkinghub.elsevier.com/retrieve/pii/S0304383517307607

426 23. Ramírez-Labrada AG, Isla D, Artal A, Arias M, Rezusta A, Pardo J, et al. The Influence 427 of Lung Microbiota on Lung Carcinogenesis, Immunity, and Immunotherapy. Trends in 428 Cancer. 2020 Feb;6(2):86-97. Available from: https://linkinghub.elsevier.com/retrieve/pii/S2405803319302651

430 24. Aragón IM, Herrera-Imbroda B, Queipo-Ortuño MI, Castillo E, Del Moral JSG, GómezMillán J, et al. The Urinary Tract Microbiome in Health and Disease. Eur Urol Focus.

433 25. Kramer H, Kuffel G, Thomas-White K, Wolfe AJ, Vellanki K, Leehey DJ, et al. Diversity 434 of the midstream urine microbiome in adults with chronic kidney disease. Int Urol Nephrol. 2018 Jun 12 [cited 2019 Sep 23];50(6):1123-30. Available from: http://www.ncbi.nlm.nih.gov/pubmed/29651696

437 26. Shoskes DA, Altemus J, Polackwich AS, Tucky B, Wang H, Eng C. The urinary 438 microbiome differs significantly between patients with chronic prostatitis/chronic pelvic 439 pain syndrome and controls as well as between patients with different clinical phenotypes. 
441 27. Siddiqui H, Lagesen K, Nederbragt AJ, Jeansson SL, Jakobsen KS. Alterations of microbiota in urine from women with interstitial cystitis. BMC Microbiol.

444 28. Nelson DE, van der Pol B, Dong Q, Revanna K V., Fan B, Easwaran S, et al. Characteristic male urine microbiomes associate with asymptomatic sexually transmitted infection. PLoS One. 2010;5(11).

447 29. Pearce MM, Hilt EE, Rosenfeld AB, Zilliox MJ, Thomas-White K, Fok C, et al. The 448 female urinary microbiome: A comparison of women with and without urgency urinary incontinence. MBio. 2014;5(4):e01283-14.

450 30. Magruder M, Sholi AN, Gong C, Zhang L, Edusei E, Huang J, et al. Gut uropathogen abundance is a risk factor for development of bacteriuria and urinary tract infection. Nat Commun. 2019 Dec 4;10(1):5521. Available from: http://www.nature.com/articles/s41467-019-13467-w

454 31. Zampini A, Nguyen AH, Rose E, Monga M, Miller AW. Defining Dysbiosis in Patients 455 with Urolithiasis. Sci Rep. 2019 Dec 1;9(1):5425. Available from: http://www.nature.com/articles/s41598-019-41977-6

457 32. Adebayo AS, Survayanshi M, Bhute S, Agunloye AM, Isokpehi RD, Anumudu CI, et al. The microbiome in urogenital schistosomiasis and induced bladder pathologies. PLoS Negl Trop Dis. 2017;11(11).

460 33. Fok CS, Gao X, Lin H, Thomas-White KJ, Mueller ER, Wolfe AJ, et al. Urinary symptoms are associated with certain urinary microbes in urogynecologic surgical patients. Int Urogynecol J. 2018 Dec 16;29(12):1765-71. Available from: 
http://link.springer.com/10.1007/s00192-018-3732-1

464 34. Gottschick C, Deng ZL, Vital M, Masur C, Abels C, Pieper DH, et al. The urinary microbiota of men and women and its changes in women during bacterial vaginosis and antibiotic treatment. Microbiome. 2017;55(1):99.

467 35. Bi H, Tian Y, Song C, Li J, Liu T, Chen Z, et al. Urinary microbiota - a potential biomarker and therapeutic target for bladder cancer. J Med Microbiol. 2019 Oct

36. Pederzoli F, Ferrarese R, Amato V, Locatelli I, Alchera E, Lucianò R, et al. Sex-specific 1;68(10):1471-8. Available from: Cancer Patients. Eur Urol Oncol. 2020;3(6):784-8.

37. Liu F, Liu A, Lu X, Zhang Z, Xue Y, Xu J, et al. Dysbiosis signatures of the microbial profile in tissue from bladder cancer. Cancer Med. 2019;8(16):6904-14.

476 38. Bučević Popović V, Šitum M, Chow CET, Chan LS, Roje B, Terzić J. The urinary microbiome associated with bladder cancer. Sci Rep. 2018;8(12157).

478 39. Chipollini J, Wright JR, Nwanosike H, Kepler CY, Batai K, Lee BR, et al. single-institution, feasibility study. Urol Oncol Semin Orig Investig. 2020 Jul;38(7):615-

482 40. Mai G, Chen L, Li R, Liu Q, Zhang H, Ma Y. Common Core Bacterial Biomarkers of 483 Bladder Cancer Based on Multiple Datasets. Biomed Res Int. 2019 Jun 19;2019:1-8. 
Catheter Collected Urine in Males with Bladder Cancer According to Disease Stage. J Urol. 2021 Jan;205(1):86-93. Available from:

42. Xu W, Yang L, Lee P, Huang WC, Nossa C, Ma Y, et al. Mini-review: perspective of the microbiome in the pathogenesis of urothelial carcinoma. Am J Clin Exp Urol. 2014;2(1):57-61.

43. Chen C, Huang Z, Huang P, Li K, Zeng J, Wen Y, et al. Profiling the Urinary Microbiota in Men with Positive versus Negative PD-L1 Expression for Non-muscle Invasive Bladder Cancer. Res Sq. 2021;

44. Hussein AA, Elsayed AS, Durrani M, Jing Z, Iqbal U, Gomez EC, et al. Investigating the association between the urinary microbiome and bladder cancer: An exploratory study. Urol Oncol Semin Orig Investig. 2021;S1078-1439.

45. Mansour B, Monyók Á, Makra N, Gajdács M, Vadnay I, Ligeti B, et al. Bladder cancer-

46. Ding J, Xu D, Pan C, Ye M, Kang J, Bai Q, et al. Current animal models of bladder 
509 48. Valli VE, Norris A, Jacobs RM, Laing E, Withrow S, Macy D, et al. Pathology of canine

$510 \quad$ bladder and urethral cancer and correlation with tumour progression and survival. J Comp

511 Pathol. 1995 Aug;113(2):113-30. Available from:

512 https://linkinghub.elsevier.com/retrieve/pii/S0021997505800271

513 49. de Brot S, Robinson B, Scase T, Grau $\square$ Roma L, Wilkinson E, Boorjian S, et al. The dog

514 as an animal model for bladder and urethral urothelial carcinoma: Comparative

515 epidemiology and histology. Oncol Lett. 2018 May 30;16:1641-9. Available from:

516 http://www.spandidos-publications.com/10.3892/ol.2018.8837

517 50. Glickman LT, Raghavan M, Knapp DW, Bonney PL, Dawson MH. Herbicide exposure 518 and the risk of transitional cell carcinoma of the urinary bladder in Scottish Terriers. J AM $519 \quad$ Vet Med Assoc. 2004;224(8):1290-7.

520 51. Decker B, Parker HG, Dhawan D, Kwon EM, Karlins E, Davis BW, et al. Homologous 521 mutation to human BRAF V600E is common in naturally occurring canine bladder cancer-evidence for a relevant model system and urine-based diagnostic test. Mol Cancer

$523 \quad$ Res. 2015;13(6):993-1002.

524 52. Coelho LP, Kultima JR, Costea PI, Fournier C, Pan Y, Czarnecki-Maulden G, et al. 525 Similarity of the dog and human gut microbiomes in gene content and response to diet. 526 Microbiome. 2018 Dec 19;6(1):72. Available from: https://microbiomejournal.biomedcentral.com/articles/10.1186/s40168-018-0450-3

528 53. Montassier E, Gastinne T, Vangay P, Al-Ghalith GA, Bruley des Varannes S, Massart S, 529 et al. Chemotherapy-driven dysbiosis in the intestinal microbiome. Aliment Pharmacol 530 Ther. 2015 Sep;42(5):515-28. Available from: http://doi.wiley.com/10.1111/apt.13302

531 54. Stringer AM, Al-Dasooqi N, Bowen JM, Tan TH, Radzuan M, Logan RM, et al. 
Biomarkers of chemotherapy-induced diarrhoea: a clinical study of intestinal microbiome alterations, inflammation and circulating matrix metalloproteinases. Support Care Cancer. 2013 Jul 10;21(7):1843-52. Available from: http://link.springer.com/10.1007/s00520-013-

55. Stewardson AJ, Gaïa N, François P, Malhotra-Kumar S, Delémont C, Martinez de Tejada with urinary tract infections: a culture-free analysis of gut microbiota. Clin Microbiol Infect. 2015 Apr;21(4):344.e1-344.e11. Available from: https://linkinghub.elsevier.com/retrieve/pii/S1198743X14001025

541 56. Suchodolski JS, Dowd SE, Westermarck E, Steiner JM, Wolcott RD, Spillmann T, et al. The effect of the macrolide antibiotic tylosin on microbial diversity in the canine small intestine as demonstrated by massive parallel $16 \mathrm{~S}$ rRNA gene sequencing. BMC Microbiol. 2009;9(1):210. Available from: lactamase protects the gut microbiome from oral beta-lactam-mediated damage in dogs.

550 58. Pilla R, Gaschen FP, Barr JW, Olson E, Honneffer J, Guard BC, et al. Effects of metronidazole on the fecal microbiome and metabolome in healthy dogs. J Vet Intern Med. 2020 Sep 28;34(5):1853-66. Available from:

554 59. Chaitman J, Ziese A-L, Pilla R, Minamoto Y, Blake AB, Guard BC, et al. Fecal Microbial 
and Metabolic Profiles in Dogs With Acute Diarrhea Receiving Either Fecal Microbiota Transplantation or Oral Metronidazole. Front Vet Sci. 2020 Apr 16;7. Available from: https://www.frontiersin.org/article/10.3389/fvets.2020.00192/full

60. Manchester AC, Webb CB, Blake AB, Sarwar F, Lidbury JA, Steiner JM, et al.

Vet Intern Med. 2019 Nov;33(6):2605-17. Available from:

61. Wolfe AJ, Toh E, Shibata N, Rong R, Kenton K, FitzGerald MP, et al. Evidence of uncultivated bacteria in the adult female bladder. J Clin Microbiol. 2012;50(4):1376-83.

62. Bajic P, Van Kuiken ME, Burge BK, Kirshenbaum EJ, Joyce CJ, Wolfe AJ, et al. Male 2020;6(2):376-82.

63. Hourigan SK, Zhu W, Wong SWW, Clemency NC, Provenzano M, Vilboux T, et al. midstream voiding versus cystoscopy. BMC Urol. 2020;20(5).

64. Pohl HG, Groah SL, Pérez-Losada M, Ljungberg I, Sprague BM, Chandal N, et al. The Neurol J. 2020;24(1):41-51.

65. Chen YB, Hochstedler B, Pham TT, Alvarez MA, Mueller ER, Wolfe AJ. The Urethral Microbiota: A Missing Link in the Female Urinary Microbiota. J Urol. 2020 Aug;204(2):303-9. Available from:

577 66. Flores-Mireles AL, Walker JN, Caparon M, Hultgren SJ. Urinary tract infections: 
epidemiology, mechanisms of infection and treatment options. Nat Rev Microbiol. 2015

67. Paalanne N, Husso A, Salo J, Pieviläinen O, Tejesvi M V., Koivusaari P, et al. Intestinal microbiome as a risk factor for urinary tract infections in children. Eur J Clin Microbiol Infect Dis. 2018 Oct 13;37(10):1881-91. Available from: http://link.springer.com/10.1007/s10096-018-3322-7

68. Mrofchak R, Madden C, Evans M V, Hale VL. Evaluating extraction methods to study canine urine microbiota. PLoS One. 2021 Jul 9;16(7):e0253989. Available from: https://dx.plos.org/10.1371/journal.pone.0253989

69. Caporaso JG, Lauber CL, Walters WA, Berg-Lyons D, Huntley J, Fierer N, et al. Ultrahigh-throughput microbial community analysis on the Illumina HiSeq and MiSeq platforms. ISME J. 2012;6:1621-1624.

70. Caporaso JG, Lauber CL, Walters WA, Berg-Lyons D, Lozupone CA, Turnbaugh PJ, et al. Global patterns of $16 \mathrm{~S}$ rRNA diversity at a depth of millions of sequences per sample. Proc Natl Acad Sci U S A. 2011;18(Supplement 1):4516-22.

593 71. Boylen E, Ram Rideout J, Dillon MR, Bokulich NA, Abnet CC, Al-Ghalith GA, et al. 594 Reproducible, interactive, scalable and extensible microbiome data science using QIIME 595 2. Nat Biotechnol. 2019;37(8):852-7.

596 72. Callahan BJ, McMurdie PJ, Rosen MJ, Han AW, Johnson AJA, Holmes SP. DADA2:

597 High-resolution sample inference from Illumina amplicon data. Nat Methods.

$598 \quad 2016 ; 13: 581-583$.

599 73. Yilmaz P, Parfrey LW, Yarza P, Gerken J, Pruesse E, Quast C, et al. The SILVA and "all600 species Living Tree Project (LTP)" taxonomic frameworks. Nucleic Acids Res. 
602 74. Quast C, Pruesse E, Yilmaz P, Gerken J, Schweer T, Yarza P, et al. The SILVA ribosomal RNA gene database project: Improved data processing and web-based tools. Nucleic Acids Res. 2013;41(Database Issue):D590-596.

75. McMurdie PJ, Holmes S. Waste Not, Want Not: Why Rarefying Microbiome Data Is Inadmissible. PLoS Comput Biol. 2014;10(4).

76. Davis NM, Proctor DM, Holmes SP, Relman DA, Callahan BJ. Simple statistical identification and removal of contaminant sequences in marker-gene and metagenomics data. Microbiome. 2018 Dec 17;6(1):226. Available from:

611 77. R Core Team. R: a langauge and environment for statistical computing. R foundation for Statistical Computing. Vienna, Austria; 2018.

613 78. McMurdie PJ, Holmes S. phyloseq: An R Package for Reproducible Interactive Analysis 614 and Graphics of Microbiome Census Data. PLoS One. 2013;8(4).

615 79. Zeng J, Zhang G, Chen C, Li K, Wen Y, Zhao J, et al. Alterations in Urobiome in Patients 616 With Bladder Cancer and Implications for Clinical Outcome: A Single-Institution Study. 617 Front Cell Infect Microbiol. 2020 Dec 15;10. Available from: the urinary microbiome in healthy dogs. PLoS One. 2017;12(5):e0177783.

621 81. Melgarejo T, Oakley BB, Krumbeck JA, Tang S, Krantz A, Linde A. Assessment of 622 bacterial and fungal populations in urine from clinically healthy dogs using 623 next $\square$ generation sequencing. J Vet Intern Med. 2021 Mar 19;jvim.16104. Available from: 
625 82. Pilla R, Suchodolski JS. The Role of the Canine Gut Microbiome and Metabolome in Health and Gastrointestinal Disease. Frontiers in Veterinary Science. 2020.

627 83. Abed J, Emgård JEM, Zamir G, Faroja M, Almogy G, Grenov A, et al. Fap2 Mediates Fusobacterium nucleatum Colorectal Adenocarcinoma Enrichment by Binding to TumorExpressed Gal-GalNAc. Cell Host Microbe. 2016 Aug;20(2):215-25. Available from: https://linkinghub.elsevier.com/retrieve/pii/S1931312816303055

84. Rubinstein MR, Baik JE, Lagana SM, Han RP, Raab WJ, Sahoo D, et al. Fusobacterium nucleatum promotes colorectal cancer by inducing $\mathrm{Wnt} / \beta \square$ catenin modulator Annexin A1. EMBO Rep. 2019 Apr 4;20(4). Available from: https://onlinelibrary.wiley.com/doi/10.15252/embr.201847638

85. Meštrović T, Matijašić M, Perić M, Čipčić Paljetak H, Barešić A, Verbanac D. The Role of Gut, Vaginal, and Urinary Microbiome in Urinary Tract Infections: From Bench to Bedside. Diagnostics. 2020 Dec 22;11(1):7. Available from: https://www.mdpi.com/2075-

639 86. Łaniewski P, Ilhan ZE, Herbst-Kralovetz MM. The microbiome and gynaecological cancer development, prevention and therapy. Nat Rev Urol. 2020 Apr 18;17(4):232-50. Available from: http://www.nature.com/articles/s41585-020-0286-z

642 87. Galperin MY. Genome Diversity of Spore-Forming Firmicutes. Driks A, Eichenberger P, editors. Microbiol Spectr. 2013 Dec 13;1(2). Available from: https://journals.asm.org/doi/10.1128/microbiolspectrum.TBS-0015-2012 
648 89. Kostic AD, Chun E, Robertson L, Glickman JN, Gallini CA, Michaud M, et al. Immune Microenvironment. Cell Host Microbe. 2013 Aug;14(2):207-15. Available from: https://linkinghub.elsevier.com/retrieve/pii/S1931312813002552

652 90. Hale VL, Jeraldo P, Chen J, Mundy M, Yao J, Priya S, et al. Distinct microbes, metabolites, and ecologies define the microbiome in deficient and proficient mismatch repair colorectal cancers. Genome Med. 2018 Dec 31;10(1):78. Available from: https://genomemedicine.biomedcentral.com/articles/10.1186/s13073-018-0586-6

91. Mitsuhashi K, Nosho K, Sukawa Y, Matsunaga Y, Ito M, Kurihara H, et al. Association of Fusobacterium species in pancreatic cancer tissues with molecular features and prognosis. Oncotarget. 2015 Mar 30;6(9):7209-20. Available from:

660 92. Ha NH, Woo BH, Kim DJ, Ha ES, Choi J Il, Kim SJ, et al. Prolonged and repetitive exposure to Porphyromonas gingivalis increases aggressiveness of oral cancer cells by promoting acquisition of cancer stem cell properties. Tumor Biol. 2015 Dec

664 93. Atanasova KR, Yilmaz Ö. Looking in the Porphyromonas gingivalis cabinet of curiosities: the microbium, the host and cancer association. Mol Oral Microbiol. 2014 Apr;29(2):5566. Available from: https://onlinelibrary.wiley.com/doi/10.1111/omi.12047

667 94. Walther-António MRS, Chen J, Multinu F, Hokenstad A, Distad TJ, Cheek EH, et al. cancer. Genome Med. 2016 Dec 25;8(1):122. Available from: 
bioRxiv preprint doi: https://doi.org/10.1101/2021.12.20 472715; this version posted December 21, 2021. The copyright holder for this preprint (which was not certified by peer review) is the author/funder, who has granted bioRxiv a license to display the preprint in perpetuity. It is made available under aCC-BY 4.0 International license.

671

672

673

674

675

676

677

678

679

680

681

682

683

684

685

686

687

688

689

690

691

692

693 
bioRxiv preprint doi: https://doi.org/10.1101/2021.12.20.472715; this version posted December 21, 2021. The copyright holder for this preprint (which was not certified by peer review) is the author/funder, who has granted bioRxiv a license to display the preprint in perpetuity. It is made available under aCC-BY 4.0 International license.

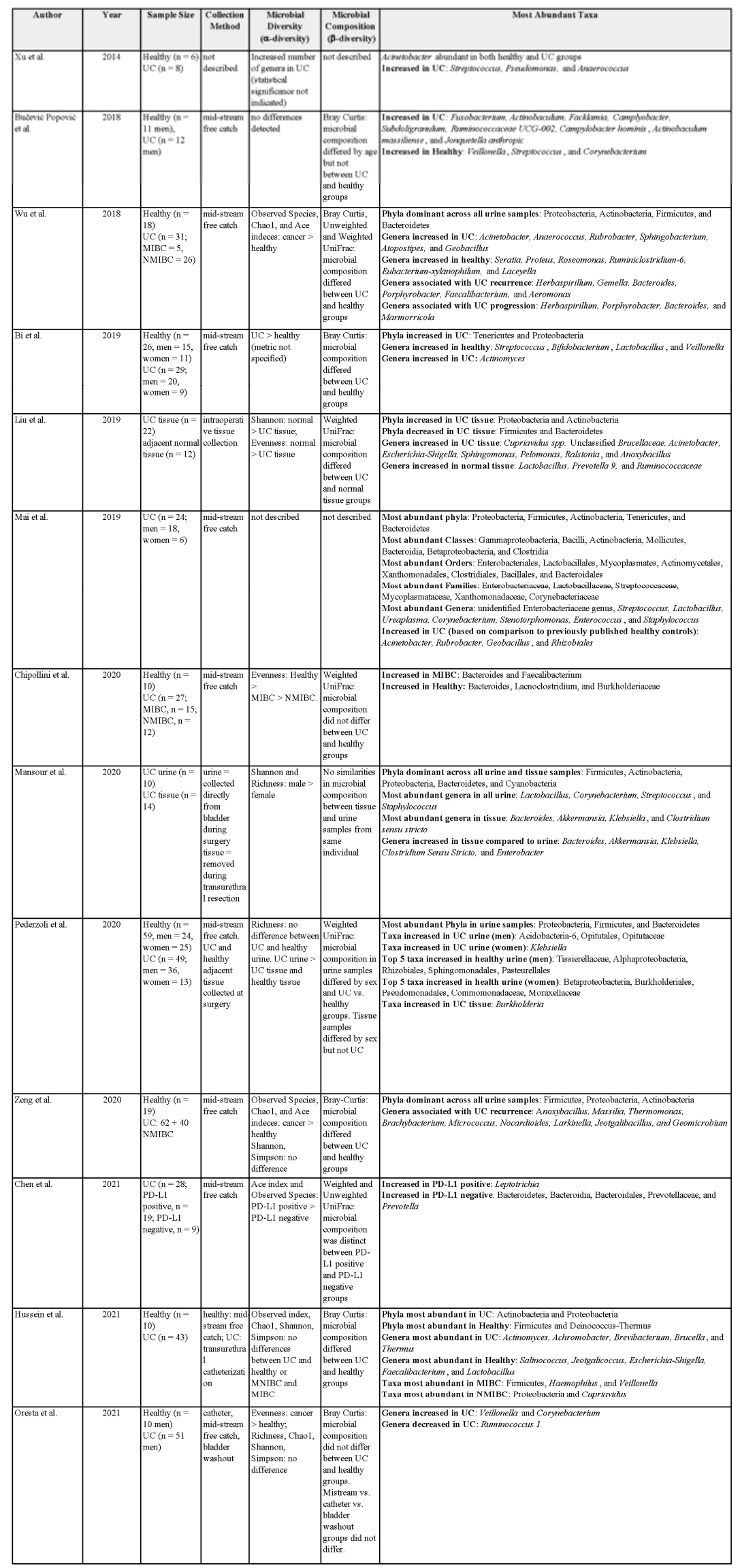




\section{Table 1: Key findings in 13 publications about the urine / tissue microbiota and urothelial}

696 carcinoma. $\mathrm{MIBC}=$ Muscle Invasive Bladder Cancer; NMIBC $=$ Non-Muscle Invasive Bladder

697 Cancer; PD-L1 = Programmed Cell Death 1 Ligand 1; UC = Urothelial Carcinoma.

698

699

700

701

702

703

704

705

706

707

708

709

710

711

712

713

714

715

716

717 


\begin{tabular}{lcc}
\hline Category & Healthy & UC \\
\hline Sex, $\mathrm{n}(\%)$ & & \\
Females & $5(71.4 \%)$ & $5(71.4 \%)$ \\
spayed & 4 & 4 \\
non-spayed & 1 & 1 \\
Males & $2(28.6 \%)$ & $2(28.6 \%)$ \\
neutered & 2 & 2 \\
non-neutered & 0 & 0 \\
Age (mean $\pm \mathrm{SD})$ & $10.1 \pm 1$ & $10.1 \pm 0.7$ \\
\hline
\end{tabular}

720 Table 2: Demographics of dogs with and without urothelial carcinoma (UC). Urine samples

721 were collected and analyzed from all dogs. Stool samples were collected and analyzed from a

722 subset of these dogs including 6 healthy ( 4 females, 2 males), and 4 with UC ( 3 females, 1 male). 
bioRxiv preprint doi: https://doi.org/10.1101/2021.12.20.472715; this version posted December 21, 2021. The copyright holder for this preprint (which was not certified by peer review) is the author/funder, who has granted bioRxiv a license to display the preprint in perpetuity. It is made available under aCC-BY 4.0 International license.

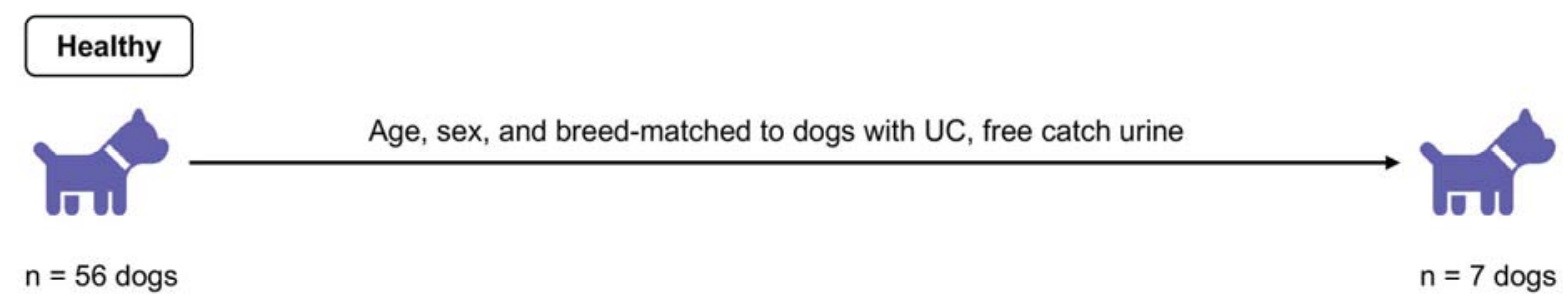

\section{Urothelial Carcinoma}

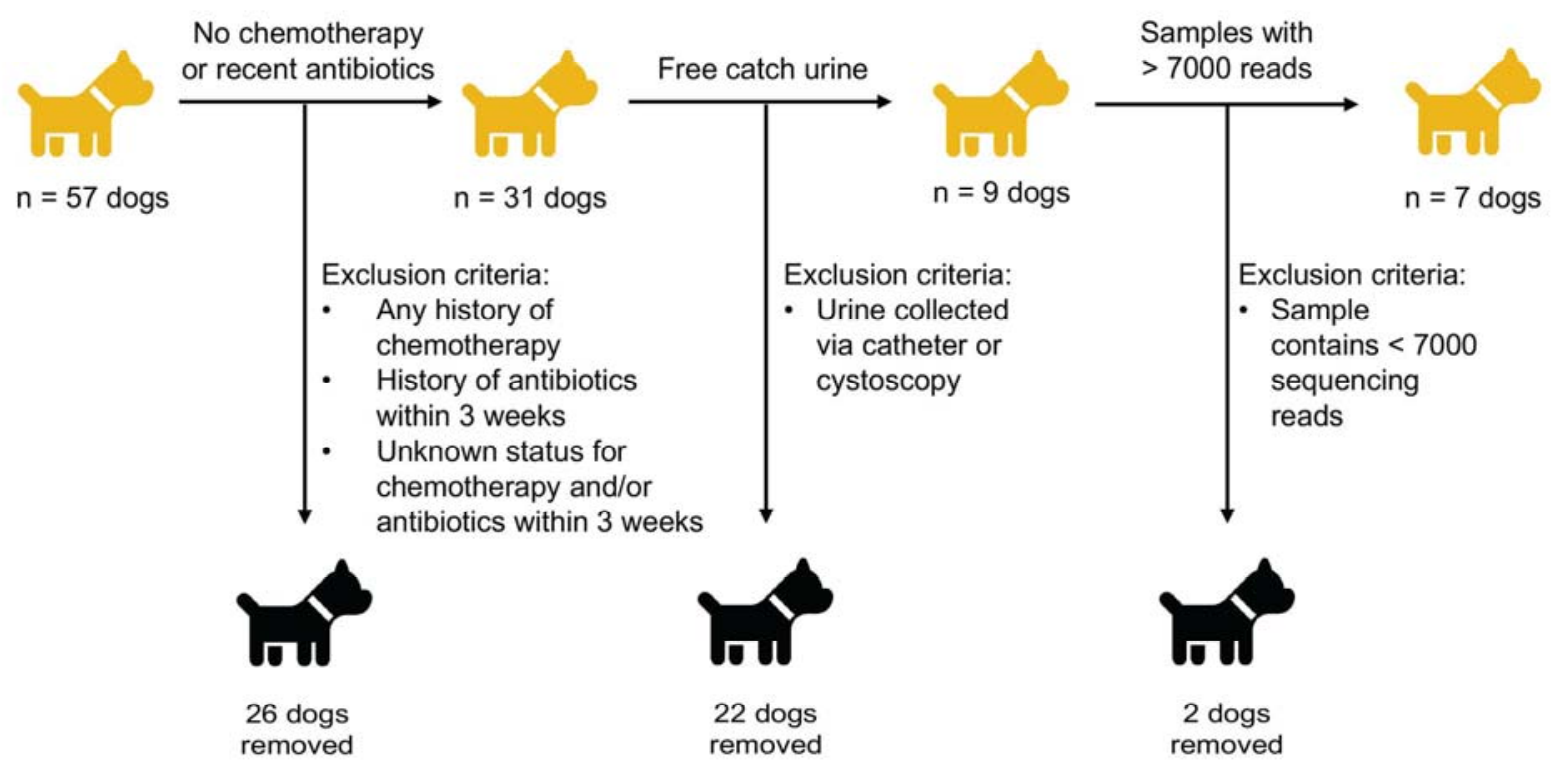

\section{Figure 1: Experimental design}


a

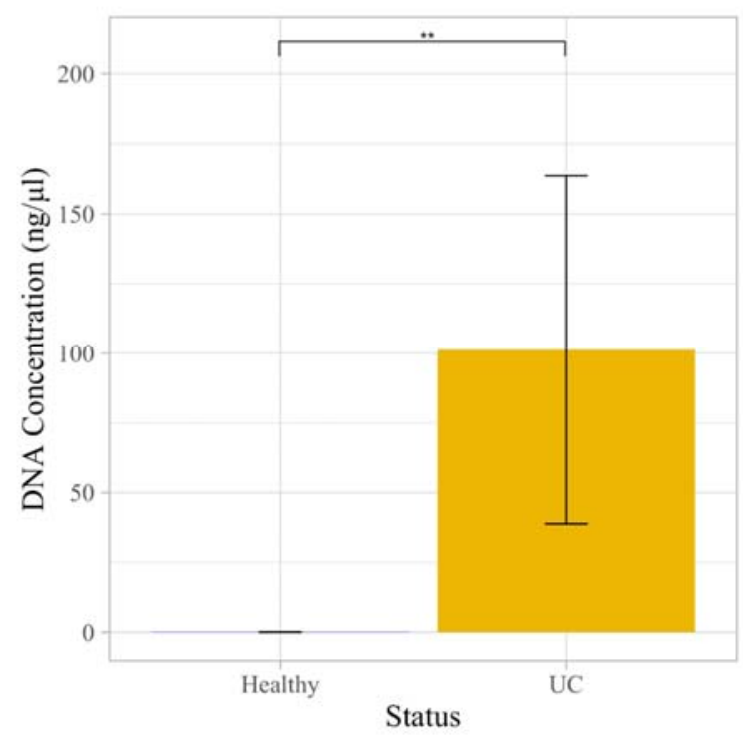

b

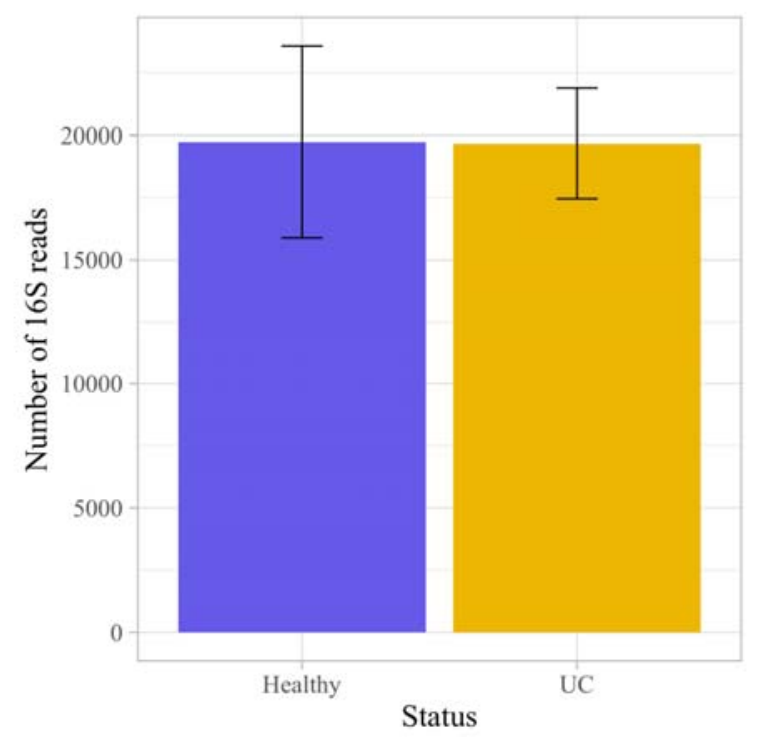

740 Figure 2: DNA concentrations and number of $16 \mathrm{~S}$ reads in the urine samples of dogs with

741 and without urothelial carcinoma (UC). (a) DNA concentrations were significantly greater in

742 dogs with UC than in healthy dogs (Wilcoxon Rank Sum test, $p=0.002$ ). (b) The number of $16 \mathrm{~S}$

743 reads did not differ significantly between groups (two-sample t-test, $p=0.99$ ). Error bars denote

744 standard error. Statistical significance is represented by stars: $*<0.05, * *<0.001, * * *<0.0001$ 
a

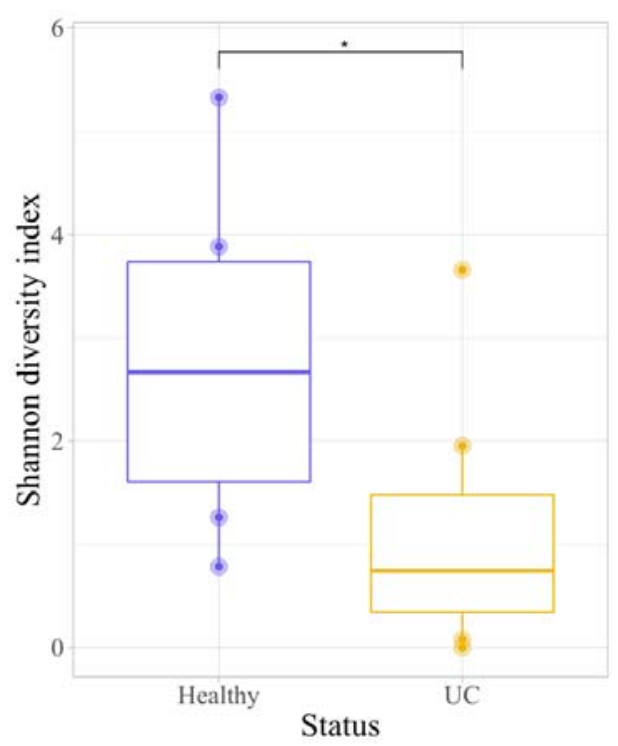

b

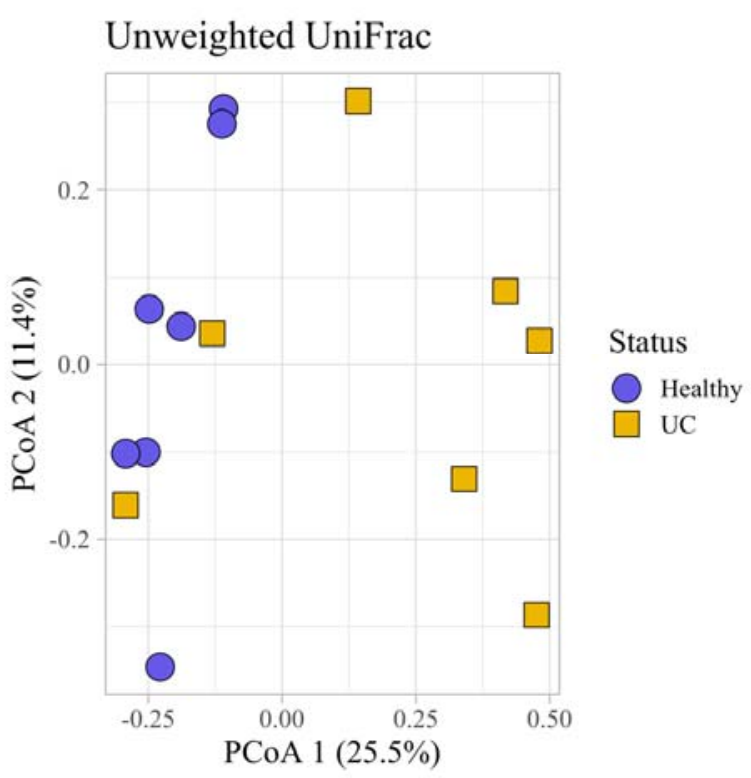

754 Figure 3: Microbial diversity and composition in the urine of dogs with and without UC.

755 (a) Healthy dogs had a significantly higher microbial diversity compared to dogs with UC as

756 measured by the Shannon diversity index (Kruskal-Wallis, $p=0.048$ ). (b) Microbial composition

757 between healthy dogs and dogs with UC also differed significantly (Unweighted UniFrac,

758 PERMANOVA, $p=0.011$ ). Error bars denote standard error. Statistical significance is

759 represented by stars: $*<0.05, * *<0.001, * * *<0.0001$ 
bioRxiv preprint doi: https://doi.org/10.1101/2021.12.20.472715; this version posted December 21, 2021. The copyright holder for this preprint (which was not certified by peer review) is the author/funder, who has granted bioRxiv a license to display the preprint in perpetuity. It is made available under aCC-BY 4.0 International license.

a

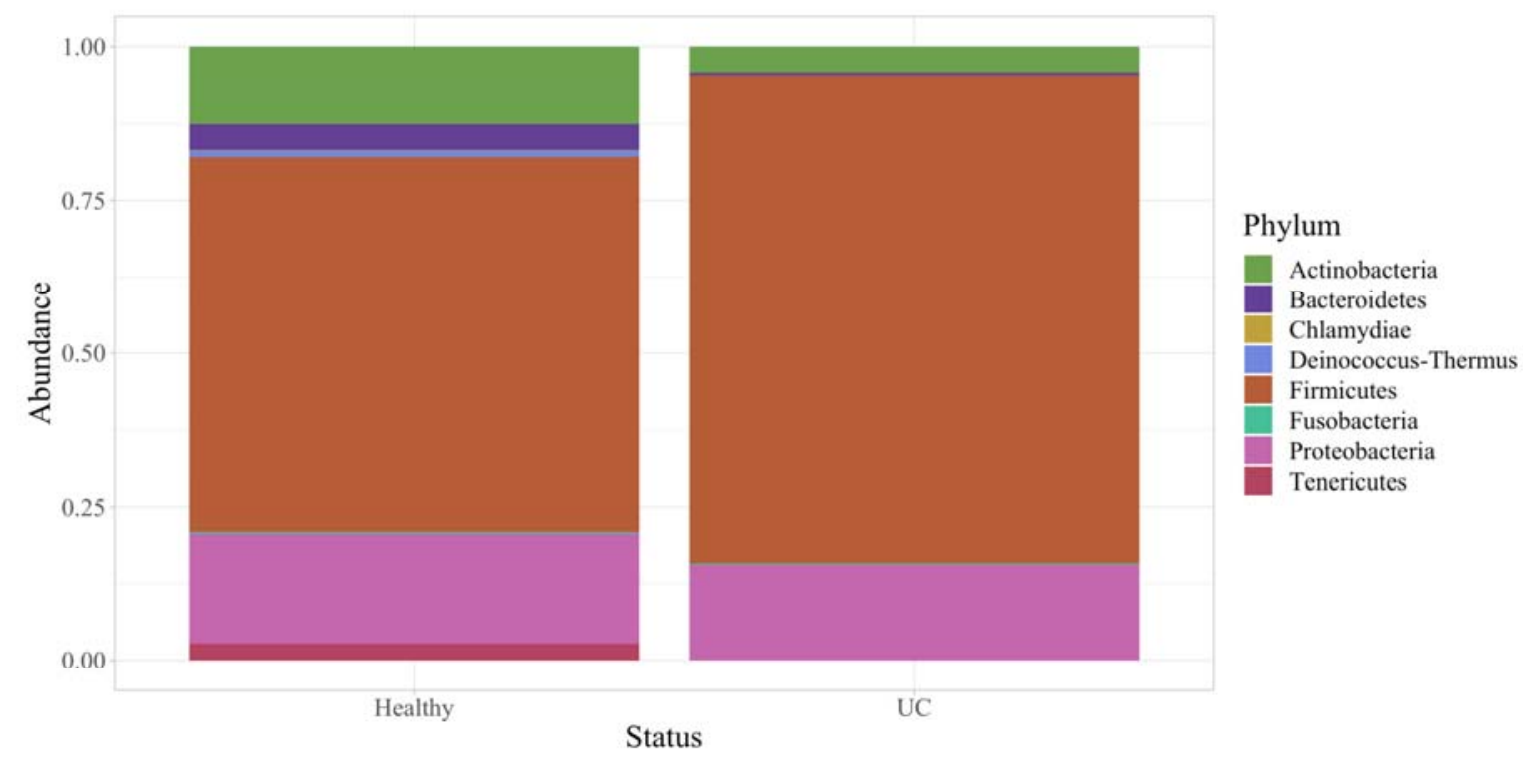

b

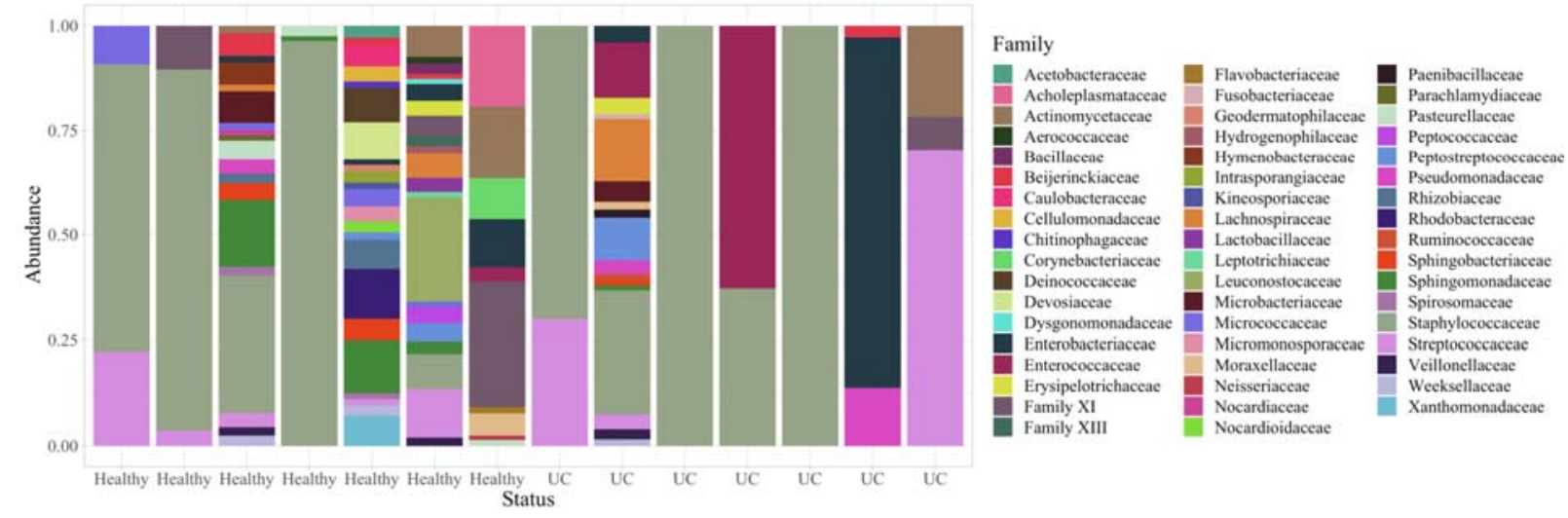

Figure 4: Phyla and family taxa bar plots of urine samples in dogs with and without UC.

(a) Phyla and (b) family relative abundances. At the family level, the taxonomic composition of

771 each sample is shown individually to demonstrate the variability across urine samples. 
a

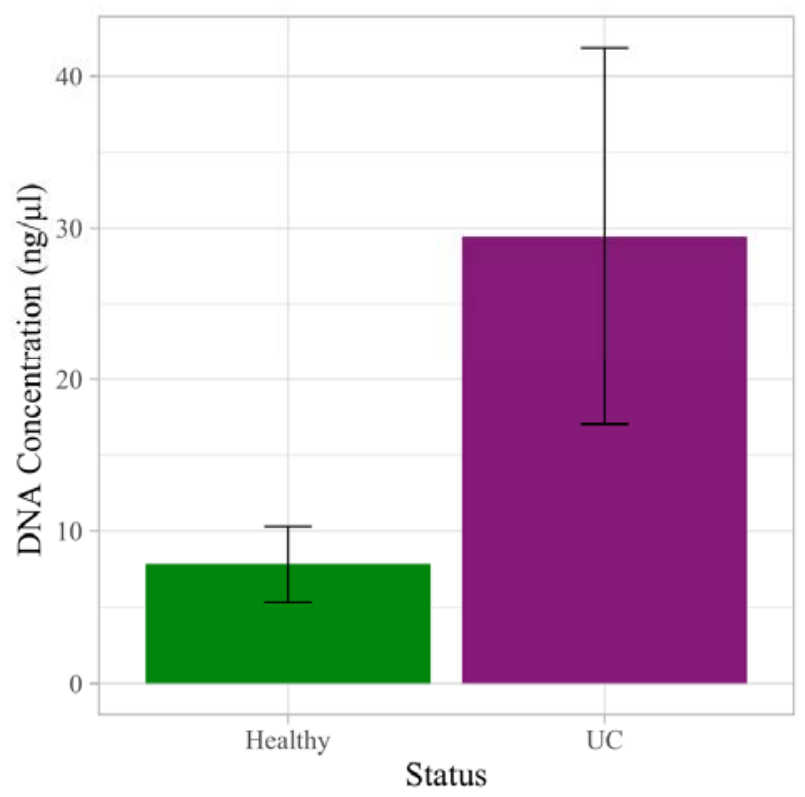

b

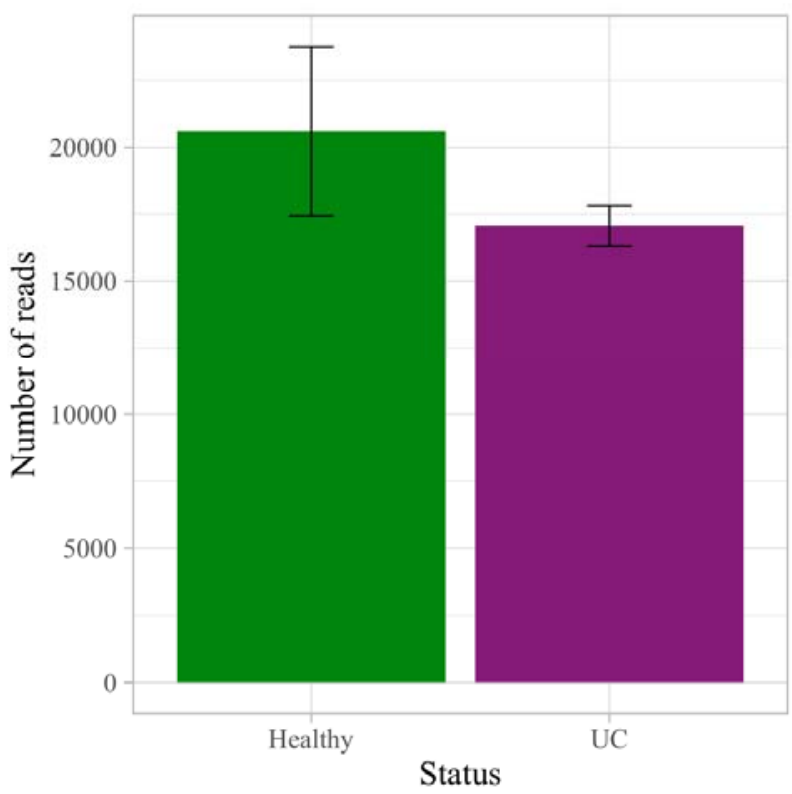

777 Figure 5: DNA concentrations and number of $16 \mathrm{~S}$ reads in the fecal samples of dogs with

778 and without UC. (a) DNA concentrations were greater (but not significantly) in dogs with UC

779 as compared to healthy dogs (Wilcoxon Rank Sum Test, $p=0.136$ ). (b) The number of $16 \mathrm{~S}$

780 reads did not differ significantly between groups (two-sample t-test, $p=0.322$ ). Error bars

781 denote standard error. 
a

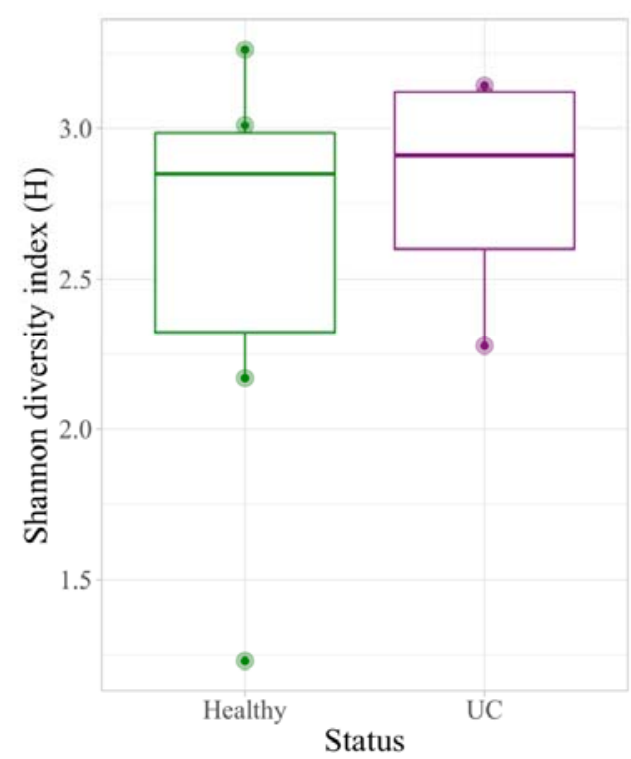

b

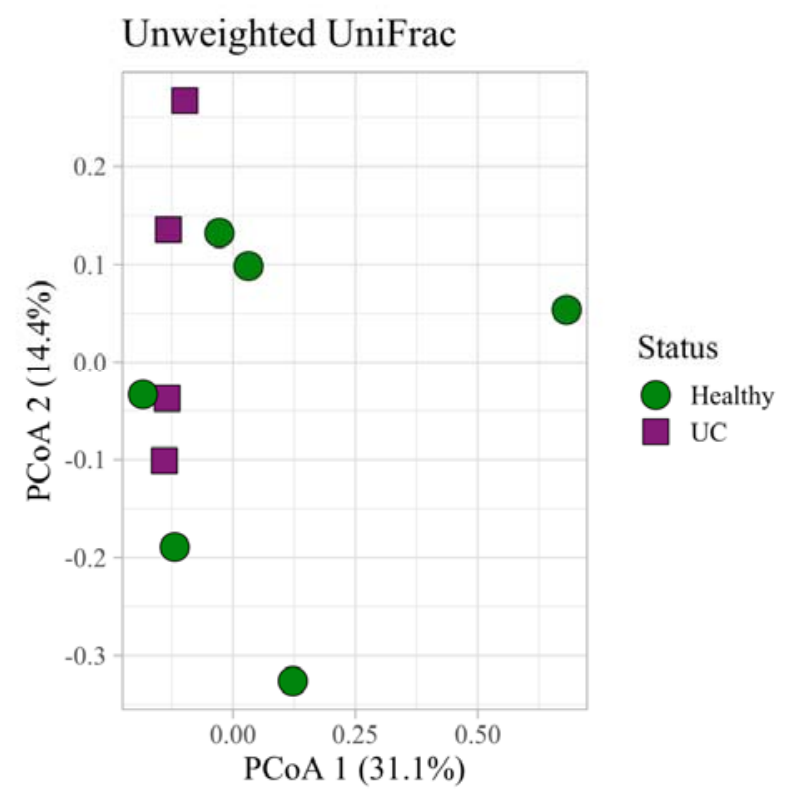

792 Figure 6: Microbial diversity and composition of fecal samples in dogs with and without

793 UC. (a) Fecal microbial diversity did not differ significantly between dogs with and without UC

794 (Kruskal-Wallis, $p=0.67$ ). (b) Microbial composition also did not differ significantly between

795 healthy dogs and dogs with UC (Unweighted UniFrac, PERMANOVA, $p=0.252$ ). Error bars

796 denote standard error. 
bioRxiv preprint doi: https://doi.org/10.1101/2021.12.20.472715; this version posted December 21, 2021. The copyright holder for this preprint (which was not certified by peer review) is the author/funder, who has granted bioRxiv a license to display the preprint in perpetuity. It is made available under aCC-BY 4.0 International license.

a

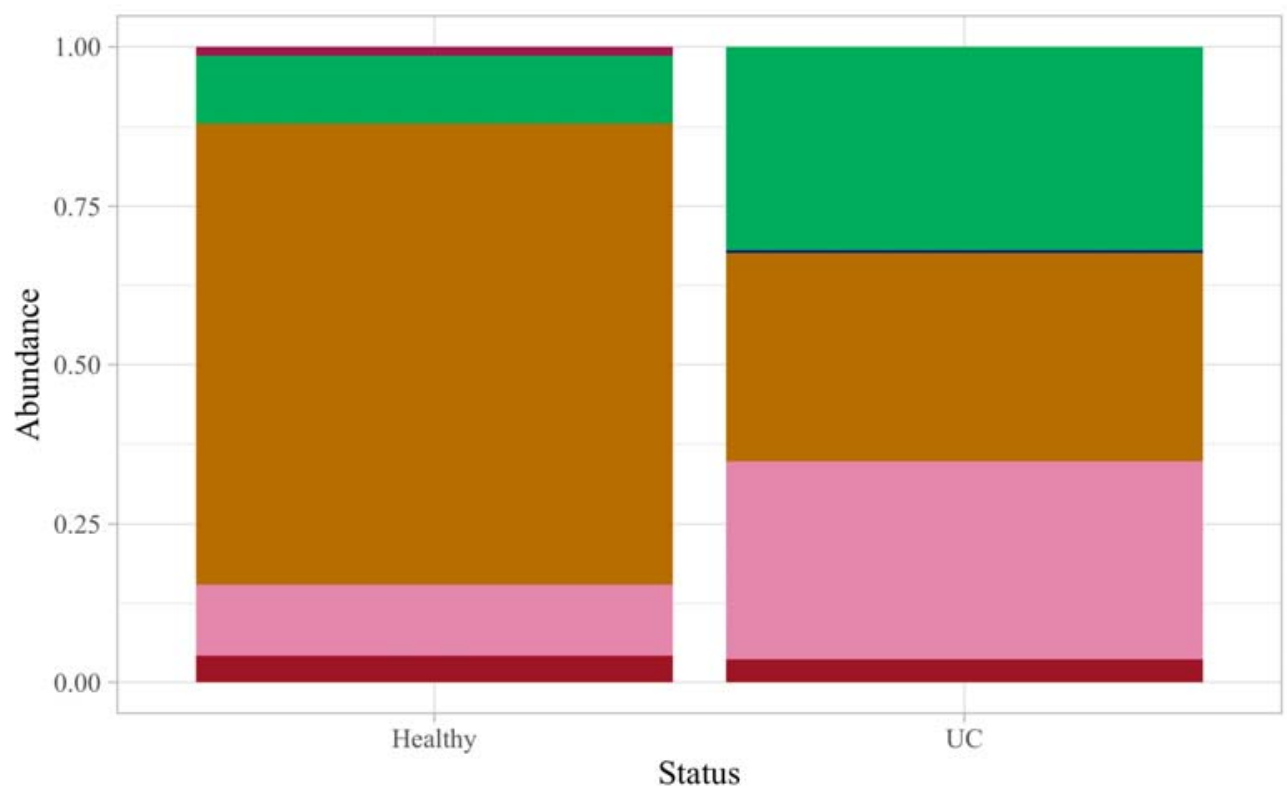

Phylum

Actinobacteria Bacteroidetes

Epsilonbacteraeota

Firmicutes

Fusobacteria

Proteobacteria

b

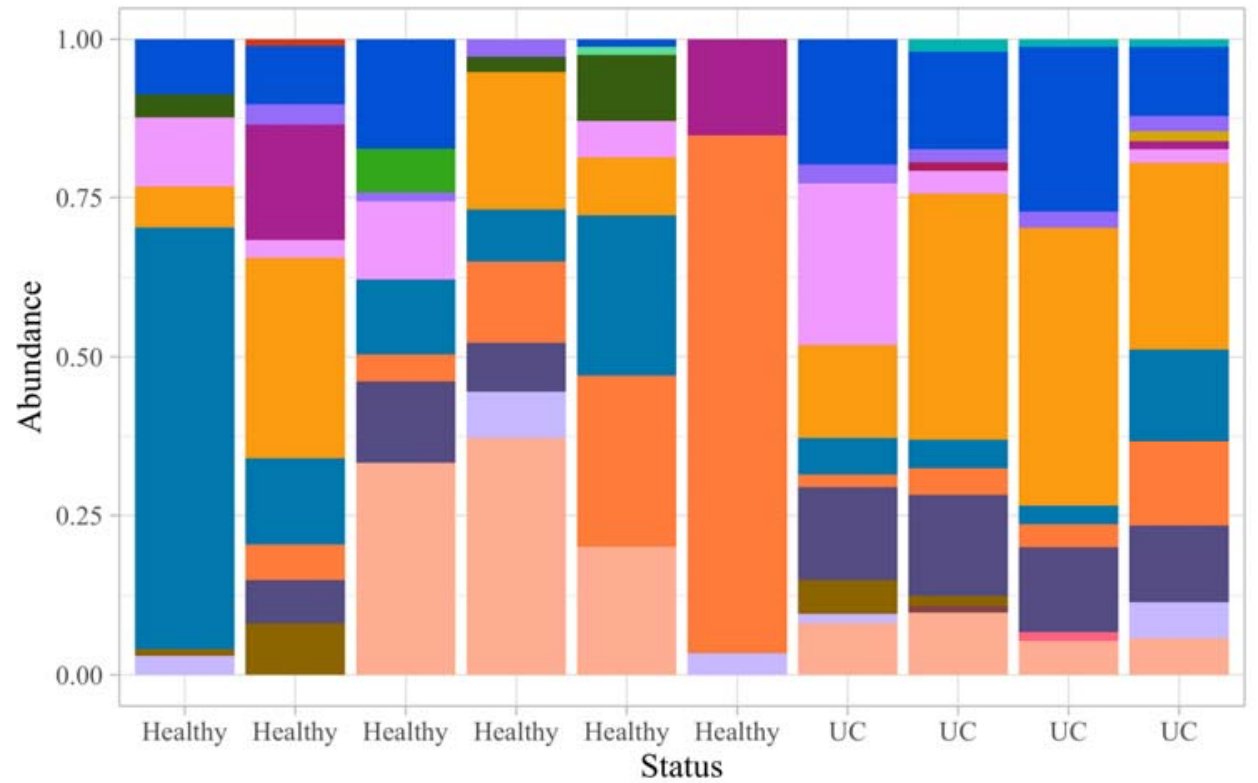

Family

- Acidaminococcaceae

Bacillaceae

Bacteroidaceae

Bifidobacteriaceae

Burkholderiaceae

Campylobacteraceae

Clostridiaceae 1

Coriobacteriaceae

Desulfovibrionaceae

Enterobacteriaceae

Erysipelotrichaceae

Fusobacteriaceae

Lachnospiraceae

Peptostreptococcaceae

Prevotellaceae

Ruminococcaceae

Streptococcaceae

Succinivibrionaceae

Tannerellaceae

Veillonellaceae

807 Figure 7: Taxa bar plots of fecal samples in dogs with and without UC. (a) Microbial phyla

808 and (b) family relative abundances. 
811 Supplemental Material:

812

\begin{tabular}{lcc}
\hline Category & Free Catch & Non-Free Catch \\
\hline Sex, $\mathrm{n}(\%)$ & $5(62.5 \%)$ & $7(62.6 \%)$ \\
Females & 4 & 6 \\
spayed & 1 & 1 \\
non-spayed & $3(37.5 \%)$ & $4(36.4 \%)$ \\
Males & 3 & 4 \\
neutered & 0 & 0 \\
non-neutered & $10.1 \pm 2$ & $9.6 \pm 1.8$ \\
Age $($ mean $\pm \mathrm{SD})$ & & \\
\hline
\end{tabular}

\section{Supplemental Table 1: Demographics of dogs with urine samples collected via free catch}

815 and non-free catch methods. All dogs had urothelial carcinoma. Eight dogs had urine collected

816 via mid-stream free catch while eleven dogs were sampled via non-free catch methods including

817 cystoscopy or catheterization.

818

819

820

821

822

823

824

825

826

827 


\begin{tabular}{|l|r|l|r|}
\hline \multicolumn{2}{|c|}{ Free Catch Urine } & Non-free Catch Urine \\
\hline Phylum & $70.3 \%$ & Firmicutes & $33 \%$ \\
\hline Firmicutes & $20.1 \%$ & Tenericutes & $26.7 \%$ \\
\hline Proteobacteria & $5.98 \%$ & Proteobacteria & $26.7 \%$ \\
\hline Bacteroidetes & $43.2 \%$ & Mycoplasma & $18.3 \%$ \\
\hline Genera & $12.6 \%$ & Escherichia-Shigella & $18.1 \%$ \\
\hline Staphylococcus & $11.4 \%$ & Enterococcus & $9.73 \%$ \\
\hline Streptococcus
\end{tabular}

832 Supplemental Table 2: Dominant taxa in urine from dogs with UC by collection method.

833 Relative abundance of the top three taxa in free catch and non-free catch urine at the phylum and

834 genera levels. All urine was collected from dogs with UC. 


\section{Putative urine contaminants (ASVs)}

D_1_Tenericutes;D_2_Mollicutes RF39;D_4_uncultured prokaryote;D_5_uncultured prokaryote;D_6__uncultured prokaryote

D_1_Deinococcus-Thermus;D_2_Deinococci;D_3_Thermales;D_4_Thermaceae;D_5_Thermus

D_1_Actinobacteria;D_2_Actinobacteria;D_3__Micrococcales;D_4_Micrococcaceae;D_5__Micrococcus

D_1_Proteobacteria;D_2_Gammaproteobacteria;D_3_Betaproteobacteriales;D_4__Burkholderiaceae;

D_5_Cupriavidus

D_1_Proteobacteria;D_2_Gammaproteobacteria;D_3_Betaproteobacteriales;D_4_Burkholderiaceae

D_1_Bacteroidetes;D_2_Bacteroidia;D_3_Bacteroidales;D_4__Prevotellaceae;D_5_Prevotella9;

D_6_uncultured bacterium

D_1_Kiritimatiellaeota;D_2_Kiritimatiellae;D_3_WCHB1-41;D_4_uncultured rumen bacterium;D_5_uncultured rumen bacterium;D_6__uncultured rumen bacterium

D_1_Bacteroidetes;D_2_Bacteroidia;D_3_Bacteroidales;D_4__Prevotellaceae

D_1_Firmicutes;D_2_Bacilli;D_3_Lactobacillales;D_4_Lactobacillaceae;D_5_Lactobacillus;

D_6__Lactobacillus iners AB-1

D_1_Firmicutes;D_2_Bacilli;D_3__Lactobacillales;D_4__Lactobacillaceae;D_5_Cytophaga

D_1__Verrucomicrobia;D_2__Verrucomicrobiae;D_3__Opitutaceae;D_4__Opitutaceae;

D_5_Lacunisphaera;D_6_Opitutus sp. WS3(2011)

D_1_Bacteroidetes;D_2_Bacteroidia;D_3_Bacteroidales;D_4_Prevotellaceae;D_5_Prevotella 9

D_1_Proteobacteria;D_2_Alphaproteobacteria;D_3__Rhizobiales;D_4_Xanthobacteraceae;

D_5_Bradyrhizobium

Putative fecal contaminants (ASVs)

D_0__Bacteria

D_1_Firmicutes;D_2_Negativicutes;D_3_Selenomonadales;D_4_Veillonellaceae;D_5_Veillonella

D_1_Firmicutes;D_2__Bacteoridia;D_3__Bacteroidales;D_4__Prevotellaceae;D_5_Prevotella 9

D_1_Firmicutes;D_2_Bacilli;D_3_Bacillales;D_4_Staphylococcaceae;D_5_Staphylococcus

D_1_Actinobacteria;D_2_Coriobacteriia;D_3_Coriobacteriales;D_4_Atopobiaceae;

D_5_Coriobacteriaceae UCG-002

D_1_Proteobacteria;D_2_Gammaproteobacteria;D_3_Enterobacteriales;D_4__Enterobacteriaceae

D_1_Actinobacteria;D_2_Coriobacteriia;D_3_Coriobacteriales;D_4_Atopobiaceae;

D_5_Coriobacteriaceae UCG-002

838 Supplemental Table 3: Contaminant ASVs. Using the frequency and prevalence methods

839 (threshold value of 0.5) in the R package decontam v.1.10.0, putative contaminant ASVs were

840 identified and bioinformatically removed prior to further analyses. 


\begin{tabular}{lcc}
\hline Category & Healthy & UC \\
\hline Sex, n $(\%)$ & $16(53.3 \%)$ & $16(53.3 \%)$ \\
Females & 15 & 15 \\
spayed & 1 & 1 \\
non-spayed & $14(46.7 \%)$ & $14(46.7 \%)$ \\
Males & 11 & 11 \\
neutered & 3 & 3 \\
non-neutered & $10 \pm 1.76$ & $10.4 \pm 1.97$ \\
Age (mean \pm SD) & & \\
\hline
\end{tabular}

\section{Supplemental Table 4: Demographics of larger canine cohort from which fecal samples}

845 were collected. Fecal samples were collected from dogs with UC $(n=30)$ and age-, sex-, breed-

846 matched healthy controls $(n=30)$. 


\begin{tabular}{|c|c|c|}
\hline & Metric & $\begin{array}{l}\text { Fecal samples from } \\
\text { healthy dogs vs. } \\
\text { dogs with UC }\end{array}$ \\
\hline \multirow{3}{*}{$\begin{array}{l}\text { Alpha } \\
\text { Diversity }\end{array}$} & $\begin{array}{c}\text { Shannon Diversity Index } \\
\text { Kruskal-Wallis }\end{array}$ & $p=0.214$ \\
\hline & $\begin{array}{c}\text { Simpson Diversity Index } \\
\text { Kruskal-Wallis }\end{array}$ & $p=0.506$ \\
\hline & $\begin{array}{c}\text { Observed Features } \\
\text { Kruskal-Wallis }\end{array}$ & $p=0.336$ \\
\hline \multirow{3}{*}{ Beta Diversity } & $\begin{array}{c}\text { Bray Curtis } \\
\text { PERMANOVA }\end{array}$ & $p=0.468$ \\
\hline & $\begin{array}{c}\text { UnWeighted UniFrac } \\
\text { PERMANOVA }\end{array}$ & $p=0.134$ \\
\hline & $\begin{array}{c}\text { Weighted UniFrac } \\
\text { PERMANOVA }\end{array}$ & $p=0.0819$ \\
\hline \multirow{3}{*}{$\begin{array}{l}\text { Differentially } \\
\text { Abundant } \\
\text { Taxa }\end{array}$} & $\begin{array}{l}\text { Phylum } \\
\text { ANCOM }\end{array}$ & $\begin{array}{l}\text { No differentially } \\
\text { abundant taxa }\end{array}$ \\
\hline & $\begin{array}{c}\text { Genus } \\
\text { ANCOM }\end{array}$ & $\begin{array}{l}\text { No differentially } \\
\text { abundant taxa }\end{array}$ \\
\hline & $\begin{array}{c}\text { ASV } \\
\text { ANCOM }\end{array}$ & $\begin{array}{l}\text { No differentially } \\
\text { abundant taxa }\end{array}$ \\
\hline
\end{tabular}

850 Supplemental Table 5. Microbial diversity and composition of fecal samples from healthy

851 dogs and dogs with UC. There were no significance differences in microbial diversity or

852 composition between dogs with UC ( $\mathrm{n}=30)$ and sex-, age-, and breed-matched healthy controls

$853(\mathrm{n}=30)$. ANCOM - Analysis of Composition of Microbiome. 


\begin{tabular}{|c|c|}
\hline $\begin{array}{l}\text { ASVs in both urine and } \\
\text { fecal samples }\end{array}$ & Taxa \\
\hline $\begin{array}{l}\text { 07124e5371867ec34213e } \\
\text { b740707a0de }\end{array}$ & $\begin{array}{l}\text { D_1__Firmicutes;D_2__Clostridia;D_3__Clostridiales;D_4__Lachnospiraceae; } \\
\text { D_5_Lachnoclostridium }\end{array}$ \\
\hline $\begin{array}{l}\text { 1345b73795b14ab0330b8 } \\
\text { ffb81b5b4aa }\end{array}$ & $\begin{array}{l}\text { D_1__Firmicutes;D_2__Clostridia;D_3_Clostridiales;D_4_LLachnospiraceae; } \\
\text { D_5_Blautia }\end{array}$ \\
\hline $\begin{array}{l}181065 \mathrm{~d} 22563 \mathrm{c} 4 \mathrm{~b} 1 \mathrm{f} 591 \mathrm{c} 6 \\
\text { a5bbee } 7355\end{array}$ & $\begin{array}{l}\text { D_1_Actinobacteria;D_2__Actinobacteria;D_3_Actinomycetales; } \\
\text { D_4_Actinomycetaceae;D_5_Actinomyces;D_6_Actinomyces sp. canine oral } \\
\text { taxon 374 }\end{array}$ \\
\hline $\begin{array}{l}\text { 1905e47315e57ce205d45 } \\
05 \mathrm{f} 1 \mathrm{a} 5 \mathrm{c} 5 \mathrm{~d} 67\end{array}$ & $\begin{array}{l}\text { D_1__Firmicutes;D_2__Bacilli;D_3__Lactobacillales;D_4_Streptococcaceae; } \\
\text { D_5_Streptococcus;D_6_Streptococcus minor }\end{array}$ \\
\hline $\begin{array}{l}\text { 1b3a2b9873a54f01302d62 } \\
\text { 9406b52aa9 }\end{array}$ & $\begin{array}{l}\text { D_1__Firmicutes;D_2__Clostridia;D_3__Clostridiales;D_4_Lachnospiraceae; } \\
\text { D_5_Blautia }\end{array}$ \\
\hline $\begin{array}{l}\text { 1cd1e7291e9803c9cdfe24 } \\
\text { a15309e043 }\end{array}$ & $\begin{array}{l}\text { D_1_Firmicutes;D_2__Clostridia;D_3__Clostridiales;D_4_Ruminococcaceae; } \\
\text { D_5_Ruminiclostridium 5;D_6_uncultured organism }\end{array}$ \\
\hline $\begin{array}{l}\text { 27046d59617e 724675b68 } \\
185 \mathrm{aeb} 33 \mathrm{~d} 4 \mathrm{a}\end{array}$ & $\begin{array}{l}\text { D_1_Firmicutes;D_2_Bacilli;D_3_Lactobacillales;D_4_Streptococcaceae; } \\
\text { D_5_Streptococcus }\end{array}$ \\
\hline $\begin{array}{l}\text { 2a39faab1cf27e5068ef885 } \\
\text { 794a3d1b1 }\end{array}$ & $\begin{array}{l}\text { D_1__Actinobacteria;D_2__Actinobacteria;D_3__Micrococcales; } \\
\text { D_4__Microbacteriaceae }\end{array}$ \\
\hline $\begin{array}{l}\text { 2cb64cfaa13ecebb815069 } \\
\text { 8e244aa026 }\end{array}$ & $\begin{array}{l}\text { D_1_Epsilonbacteraeota;D_2_Campylobacteria;D_3_Camplybacterales; } \\
\text { D_4_Helicobacteraceae;D_5__Helicobacter;D_6_Helicobacter canis }\end{array}$ \\
\hline $\begin{array}{l}35815582 \mathrm{~b} 2 \mathrm{cf} 31 \mathrm{eb} 986673 \\
\text { cddccb558c }\end{array}$ & $\begin{array}{l}\text { D_1_Firmicutes;D_2_Clostridia;D_3_CClostridiales;D_4_Peptostreptococcaceae; } \\
\text { D_5_peptoclostridium;D_6_uncultured bacterium }\end{array}$ \\
\hline $\begin{array}{l}\text { 382cccf9f2613e42c60288 } \\
\text { 2e5efba519 }\end{array}$ & $\begin{array}{l}\text { D_1__Firmicutes;D_2_Clostridia;D_3__Clostridiales;D_4_Lachnospiraceae; } \\
\text { D_5_Blautia }\end{array}$ \\
\hline $\begin{array}{l}\text { 38ad78b86309fa98eaea53 } \\
\text { bac8579237 }\end{array}$ & $\begin{array}{l}\text { D_1_Firmicutes;D_2_CClostridia;D_3_Clostridiales;D_4__Clostridiaceae } \\
\text { 1;D_5_Candidatus Arthromitus;D_6_uncultured bacterium }\end{array}$ \\
\hline $\begin{array}{l}\text { 3acf68a82e28a71226cc15 } \\
195277 f 39 a\end{array}$ & $\begin{array}{l}\text { D_1__Firmicutes;D_2__Clostridia;D_3__Clostridiales;D_4_LLachnospiraceae; } \\
\text { D_5_uncultured;D_6_uncultured organism }\end{array}$ \\
\hline $\begin{array}{l}3 \mathrm{c} 4 \mathrm{c} 352 \mathrm{e} 66306770 \mathrm{ce} 10 \mathrm{~d} 3 \\
\text { ac128d0ca8 }\end{array}$ & $\begin{array}{l}\text { D_1__Firmicutes;D_2_Bacilli;D_3_Lactobacillales;D_4_Streptococcaceae; } \\
\text { D_5_Lactococcus }\end{array}$ \\
\hline $\begin{array}{l}\text { 42aa3a600f30a5267eea5a } \\
34 \mathrm{~d} 8655853\end{array}$ & $\begin{array}{l}\text { D_1__Firmicutes;D_2_Clostridia;D_3__Clostridiales;D_4_LLachnospiraceae; } \\
\text { D_5_uncultured }\end{array}$ \\
\hline $\begin{array}{l}\text { 4611ef696d9c9f16982f08 } \\
\text { 86174522fe }\end{array}$ & $\begin{array}{l}\text { D_1__Firmicutes;D_2_Clostridia;D_3_Clostridiales;D_4_LLachnospiraceae; } \\
\text { D_5_Epulopiscium }\end{array}$ \\
\hline $\begin{array}{l}\text { 4952ad8a58b2e7d70d531 } \\
5 \mathrm{ce} 330442 \mathrm{bb}\end{array}$ & $\begin{array}{l}\text { D_1_Fusobacteria;D_2_Fusobacteriia;D_3_Fusobacteriales; } \\
\text { D_4_Fusobacteriaceae;D_5_Fusobacterium }\end{array}$ \\
\hline $\begin{array}{l}\text { 4a654a475be76c770508d } \\
\text { 1ea6a9771d9 }\end{array}$ & $\begin{array}{l}\text { D_1_Firmicutes;D_2_Erysipelotrichia;D_3_Erysipelotrichales; } \\
\text { D_4_Erysipelotrichiaceae;D_5__Faecalitalea;D_6_Eubacterium sp. 1-5 }\end{array}$ \\
\hline $\begin{array}{l}\text { 4d74ef18790f690b2acf5fc } \\
60 f 89 c 222\end{array}$ & $\begin{array}{l}\text { D_1__Firmicutes;D_2_Clostridia;D_3__Clostridiales;D_4_Lachnospiraceae; } \\
\text { D_5_[Ruminococcus] gauvreauii group }\end{array}$ \\
\hline $\begin{array}{l}\text { 4f1d5517aa4ce179ae9241 } \\
\text { d5a5b3796d }\end{array}$ & D_1_Firmicutes;D_2_Bacilli;D_3_Bacillales;D_4_Bacillaceae;D_5_Bacillus \\
\hline $\begin{array}{l}\text { 52990f305d65b7df7dedd8 } \\
87 \mathrm{cc} 08988 \mathrm{f}\end{array}$ & $\begin{array}{l}\text { D_1__Firmicutes;D_2_Negativicutes;D_3_Selenomonadales; } \\
\text { D_4_Veillonellaceae;D_5_Megamonas }\end{array}$ \\
\hline $\begin{array}{l}\text { 52ef51c7bec642ab72d7ce } \\
474821 \mathrm{~b} 108\end{array}$ & $\begin{array}{l}\text { D_1_Actinobacteria;D_2_Actinobacteria;D_3__Micrococcales; } \\
\text { D_4_Micrococcaceae;D_5_Rothia }\end{array}$ \\
\hline $\begin{array}{l}\text { 601426df62ac2005c0a78b } \\
\text { be617425a4 }\end{array}$ & $\begin{array}{l}\text { D_1__Actinobacteria;D_2__Actinobacteria;D_3_Actinomycetales; } \\
\text { D_4_Actinomycetaceae;D_5_Actinomyces;D_6_Actinomyces coleocanis }\end{array}$ \\
\hline $\begin{array}{l}\text { 6019612a56660d54c57f12 } \\
299224759 \mathrm{~d}\end{array}$ & $\begin{array}{l}\text { D_1_Firmicutes;D_2_EErysipelotrichia;D_3__Eryspielotrichales; } \\
\text { D_4_Erysipelotrichaceae;D_5_Catenibacterium }\end{array}$ \\
\hline $\begin{array}{l}\text { 61b2e2fc40303b1f0f19c1 } \\
017 f 258 b a c\end{array}$ & $\begin{array}{l}\text { D_1_Firmicutes;D_2__Clostridia;D_3_Clostridiales;D_4_Peptostreptococcaceae; } \\
\text { D_5_terrisporobacter;D_6_uncultured bacterium }\end{array}$ \\
\hline
\end{tabular}




\begin{tabular}{|c|c|}
\hline $\begin{array}{l}\text { 674e202dd30eab31fd } 8262 \\
55 \text { caec } 43 \mathrm{e} 1\end{array}$ & $\begin{array}{l}\text { D_1__Firmicutes;D_2__Negativicutes;D_3__Selenomonadales; } \\
\text { D_4_Acidaminococcaceae;D_5_Phascolarctobacterium;D_6_uncultured } \\
\text { Veillonellaceae bacterium }\end{array}$ \\
\hline $\begin{array}{l}\text { 682c96e343759d3583a2a } \\
293 f a 4 e 0160\end{array}$ & $\begin{array}{l}\text { D_1__Firmicutes;D_2__Clostridia;D_3_Clostridiales;D_4__Lachnospiraceae; } \\
\text { D_5_Lachnoclostridium;D_6_Lachnospiraceae bacterium 2_1_46FAA }\end{array}$ \\
\hline $\begin{array}{l}\text { 6a081f2b1b45ee5773bb94 } \\
\text { 7b977f5893 }\end{array}$ & $\begin{array}{l}\text { D_1__Firmicutes;D_2__Clostridia;D_3_Clostridiales;D_4__Lachnospiraceae; } \\
\text { D_5_uncultured }\end{array}$ \\
\hline $\begin{array}{l}\text { 6e441eb1e3bc74bb8a5ec4 } \\
\text { ff24b11147 }\end{array}$ & $\begin{array}{l}\text { D_1_Firmicutes;D_2_Bacilli;D_3_LLactobacillales;D_4_Lactobacillaceae; } \\
\text { D_5_Lactobacillus }\end{array}$ \\
\hline $\begin{array}{l}\text { 6fdb8a40fc3f65447a2ea0b } \\
\text { 3c21bbd68 }\end{array}$ & $\begin{array}{l}\text { D_1__Bacteroidetes;D_2__Bacteroidia;D_3_Bacteroidales;D_4__Bacteroidaceae; } \\
\text { D_5_Bacteroides;D_6_Bacteroides stercoris ATCC 43183 }\end{array}$ \\
\hline $\begin{array}{l}\text { 730125adfc6eae51053161 } \\
\text { e4a29f2bc9 }\end{array}$ & $\begin{array}{l}\text { D_1__Firmicutes;D_2__Bacilli;D_3_LLactobacillales;D_4_Enterococcaceae; } \\
\text { D_5_Enterococcus }\end{array}$ \\
\hline $\begin{array}{l}\text { 7439a1dc0a2e589a4605ce } \\
\text { fd7fcc6cb4 }\end{array}$ & $\begin{array}{l}\text { D_1__Actinobacteria;D_2__Coriobacteriia;D_3_CCoriobacteriales; } \\
\text { D_4_Coriobacteriaceae;D_5_Collinsella }\end{array}$ \\
\hline $\begin{array}{l}5009242 \text { aaa1cde } 47 \\
998\end{array}$ & $\begin{array}{l}\text { D_1__Firmicutes;D_2__Clostridia;D_3__Clostridiales;D_4__Lachnospiraceae; } \\
\text { D_5_Blautia;D_6_uncultured Blautia sp. }\end{array}$ \\
\hline $\begin{array}{l}01 \mathrm{~d} 85567 \mathrm{f} 7117 \\
\text { dce }\end{array}$ & $\begin{array}{l}\text { D_1__Firmicutes;D_2_Erysipelotrichia;D_3_Erysipelotrichales; } \\
\text { D_4_Erysipelotrichiaceae;D_5_Faecalitalea;D_6_Erysipelatoclostridum }\end{array}$ \\
\hline $\begin{array}{l}\text { 76815f71f41950d2e2d481 } \\
\text { b6b730f3d8 }\end{array}$ & $\begin{array}{l}\text { D_1_Firmicutes;D_2_Clostridia;D_3_Clostridiales;D_4_Ruminococcaceae; } \\
\text { D_5_Faecalibacterium }\end{array}$ \\
\hline $\begin{array}{l}777 \mathrm{de} 77 \mathrm{e} \\
2 \mathrm{~b} 03 \mathrm{f} 8 \mathrm{eae}\end{array}$ & D_1_Firmicutes;D_2_Bacilli;D_3_Bacillales;D_4_Bacillaceae;D_5_Bacillus \\
\hline $217263 f 67621$ & $\begin{array}{l}\text { D_1__Firmicutes;D_2__Bacilli;D_3_Lactobacillales;D_4_Streptococcaceae; } \\
\text { D_5_Streptococcus }\end{array}$ \\
\hline $\begin{array}{l}84 \mathrm{e} 088771 \mathrm{adb} 5 \mathrm{cfc} 2 \mathrm{e} 134 \mathrm{c} \\
\text { 9bad18c76a }\end{array}$ & $\begin{array}{l}\text { D_1_Firmicutes;D_2_Clostridia;D_3__Clostridiales;D_4_Peptostreptococcaceae; } \\
\text { D_5_Clostridioides;D_6_Clostridioides difficile }\end{array}$ \\
\hline $\begin{array}{l}\text { 877d42a21d6e5694161ea } \\
\text { 485ce3dacf8 }\end{array}$ & $\begin{array}{l}\text { D_1_Firmicutes;D_2_Clostridia;D_3__Clostridiales;D_4_Ruminococcaceae; } \\
\text { D_5_Flavonifractor }\end{array}$ \\
\hline $\begin{array}{l}\text { 87a5ae82db511f591c640d } \\
9 \mathrm{ad} 67321 \mathrm{fc}\end{array}$ & $\begin{array}{l}\text { D_1__Actinobacteria;D_2__Actinobacteria;D_3__Micromonosporales; } \\
\text { D_4__Micromonosporaceae;D_5_Actinoplanes }\end{array}$ \\
\hline $\begin{array}{l}91 \text { beca23d467a7cb152b78 } \\
\text { f9505e650e }\end{array}$ & $\begin{array}{l}\text { D_1__Firmicutes;D_2_Erysipelotrichia;D_3_Erysipelotrichales; } \\
\text { D_4_Erysipelotrichiaceae;D_5_Allobaculum;D_6_Allobaculum stercoricanis } \\
\text { DSM } 13633\end{array}$ \\
\hline $\begin{array}{l}\text { 9d135cd7fd9b670ce5fdccf } \\
\text { ce8851183 }\end{array}$ & $\begin{array}{l}\text { D_1__Firmicutes;D_2_Clostridia;D_3__Clostridiales;D_4_Lachnospiraceae; } \\
\text { D_5_Blautia }\end{array}$ \\
\hline $\begin{array}{l}\text { a3000823e9ab005bb353ff } \\
\text { 4e1e20eed } 8\end{array}$ & $\begin{array}{l}\text { D_1_Firmicutes;D_2__Clostridia;D_3_Clostridiales;D_4__Clostridiaceae } \\
\text { 1;D_5_Clostridium sensu stricto 1 }\end{array}$ \\
\hline $\begin{array}{l}\text { a3d3d817d8183e0d74175 } \\
\text { e4afbe65409 }\end{array}$ & $\begin{array}{l}\text { D_1__Proteobacteria;D_2__Gammaproteobacteria;D_3_Pasteurellales; } \\
\text { D_4_Pasteurellaceae;D_5_Pasteurella;D_6_Pasteurella multocida }\end{array}$ \\
\hline $\begin{array}{l}\text { a80abf00da9c833cb1faaa9 } \\
\text { 707727dda }\end{array}$ & $\begin{array}{l}\text { D_1__Firmicutes;D_2__Bacilli;D_3__Lactobacillales;D_4_Streptococcaceae; } \\
\text { D_5_Streptococcus }\end{array}$ \\
\hline $\begin{array}{l}\text { ab9782e24971a281bf5c73 } \\
\text { c33d9ad73d }\end{array}$ & $\begin{array}{l}\text { D_1_Firmicutes;D_2_Erysipelotrichia;D_3_Erysipelotrichales; } \\
\text { D_4_Erysipelotrichaceae;D_5_Faecalitalea;D_6_[Eubacterium] dolichum }\end{array}$ \\
\hline $\begin{array}{l}\text { b0d75fc101fefcde86c03b7 } \\
\text { cfdb39caf }\end{array}$ & $\begin{array}{l}\text { D_1__Actinobacteria;D_2__Actinobacteria;D_3_Corynebacteriales; } \\
\text { D_4_Corynebacteriaceae;D_5_Corynebacterium } 1\end{array}$ \\
\hline $\begin{array}{l}\text { b7095a583ea62033ff918e } \\
\text { 2187652b27 }\end{array}$ & $\begin{array}{l}\text { D_1__Bacteroidetes;D_2_Bacteroidia;D_3__Bacteroidales; } \\
\text { D_4_Porphyromonadaceae;D_5_Porphyromonas;D_6_Porphyromonas sp. COT- } \\
\text { 052_OH4946 }\end{array}$ \\
\hline $\begin{array}{l}\text { bd4017ad4efac59720e2d1 } \\
\text { 64da18ace4 }\end{array}$ & $\begin{array}{l}\text { D_1__Firmicutes;D_2__Clostridia;D_3__Clostridiales;D_4_Clostridiaceae1; } \\
\text { D_5_Clostridium sensu stricto } 1 ; \mathrm{D} \text { _6_Clostridium baratii }\end{array}$ \\
\hline $\begin{array}{l}\text { c5073ccb362bfa533ad671 } \\
\text { fac3babb80 }\end{array}$ & $\begin{array}{l}\text { D_1__Firmicutes;D_2__Clostridia;D_3__Clostridiales;D_4_Lachnospiraceae; } \\
\text { D_5_Blautia;D_6_Blautia sp. YHC-4 }\end{array}$ \\
\hline $\begin{array}{l}\text { c6bedd5b82d0f92872c6e9 } \\
\text { d7435a172e }\end{array}$ & $\begin{array}{l}\text { D_1_Firmicutes;D_2_Clostridia;D_3__Clostridiales;D_4_Ruminococcaceae; } \\
\text { D_5_Ruminococceae UCG-014;D_6__uncultured organism }\end{array}$ \\
\hline
\end{tabular}




\begin{tabular}{|c|c|}
\hline $\begin{array}{l}\text { c8f1df932d5f877f524cd2c } \\
16367 \mathrm{e} 721\end{array}$ & $\begin{array}{l}\text { D_1__Actinobacteria;D_2__Coriobacteriia;D_3_Coriobacteriales; } \\
\text { D_4_Coriobacteriaceae;D_5_Collinsella;D_6_CCollinsella stercoris }\end{array}$ \\
\hline $\begin{array}{l}\text { cc8f83128875d60f9e1de4 } \\
\text { 33a207ce81 }\end{array}$ & $\begin{array}{l}\text { D_1_Epsilonbacteraeota;D_2_Campylobacteria;D_3_Camplybacterales; } \\
\text { D_4_Campylobacteraceae;D_5_Campylobacter }\end{array}$ \\
\hline $\begin{array}{l}\text { d3d0bd88ddd06bf6e49cde } \\
1 \text { cdff07e9b }\end{array}$ & $\begin{array}{l}\text { D_1__Firmicutes;D_2_Erysipelotrichia;D_3_EErysipelotrichales; } \\
\text { D_4_Erysipelotrichaceae;D_5_Erysipelatoclostridium }\end{array}$ \\
\hline $\begin{array}{l}\text { dae3d6aa2560755d95861 } \\
8047492 \mathrm{c} 1 \mathrm{f} 2\end{array}$ & $\begin{array}{l}\text { D_1_Firmicutes;D_2_Bacilli;D_3_Lactobacillales;D_4__Streptococcaceae; } \\
\text { D_5_Streptococcus }\end{array}$ \\
\hline $\begin{array}{l}\text { e1002cca0084443ac173b0 } \\
37 \mathrm{~d} 6049 \mathrm{~d} 8 \mathrm{~b}\end{array}$ & $\begin{array}{l}\text { D_1__Firmicutes;D_2__Clostridia;D_3__Clostridiales;D_4__Lachnospiraceae; } \\
\text { D_5_[Ruminococcus] torques group;D_6__uncultured Clostridium sp. }\end{array}$ \\
\hline $\begin{array}{l}\text { e46e5d3e3462c7351e1dc5 } \\
\text { 2ec42e64cf }\end{array}$ & $\begin{array}{l}\text { D_1_Actinobacteria;D_2_Actinobacteria;D_3_Corynebacteriales; } \\
\text { D_4_Corynebacteriaceae }\end{array}$ \\
\hline $\begin{array}{l}\text { e49f8561188c9050a9a3e3 } \\
\text { af2aa75c24 }\end{array}$ & $\begin{array}{l}\text { D_1_Bacteroidetes;D_2__Bacteroidia;D_3__Bacteroidales;D_4__Bacteroidaceae;D_ } \\
\text { 5_Bacteroides;D_6_uncultured bacterium }\end{array}$ \\
\hline $\begin{array}{l}\text { ee10da4f77a1cf2cbf3146a } \\
\text { f2563a05c }\end{array}$ & $\begin{array}{l}\text { D_1__Fusobacteria;D_2_Fusobacteriia;D_3_Fusobacteriales; } \\
\text { D_4_Fusobacteriaceae;D_5_Fusobacterium;D_6_gut metagenome }\end{array}$ \\
\hline $\begin{array}{l}\text { f8b7aef6c94fcbe1b4793ff } \\
\text { c3304bf0b }\end{array}$ & $\begin{array}{l}\text { D_1__Firmicutes;D_2_Erysipelotrichia;D_3_Erysipelotrichales; } \\
\text { D_4_Erysipelotrichaceae;D_5_Catenibacterium }\end{array}$ \\
\hline $\begin{array}{l}\text { f8cc743ae9448d9472ef8d } \\
3914262 \mathrm{ccb}\end{array}$ & $\begin{array}{l}\text { D_1__Proteobacteria;D_2__Gammaproteobacteria;D_3_Enterobacteriales; } \\
\text { D_4_Enterobacteriaceae;D_5_Escherichia-Shigella }\end{array}$ \\
\hline $\begin{array}{l}\text { f957a7c9e0410797ffaa0be } \\
\text { 222cb0085 }\end{array}$ & $\begin{array}{l}\text { D_1__Actinobacteria;D_2_Coriobacteriia;D_3_Coriobacteriales; } \\
\text { D_4_Eggerthellaceae;D_5_Slackia }\end{array}$ \\
\hline $\begin{array}{l}\text { fa0dcff3fde22b426ce94d8 } \\
\text { c91f56a17 }\end{array}$ & $\begin{array}{l}\text { D_1__Firmicutes;D_2_Clostridia;D_3_Clostridiales;D_4_Lachnospiraceae; } \\
\text { D_5_[Ruminococcus] gnavus group }\end{array}$ \\
\hline $\begin{array}{l}\text { fa4dd8c953b8a69498d154 } \\
\text { 3bf15a4190 }\end{array}$ & D_1_Firmicutes;D_2_Clostridia;D_3_Clostridiales;D_4_Lachnospiraceae \\
\hline $\begin{array}{l}\text { fe9db134f6a44b3e5ac3ed } \\
1315920582\end{array}$ & $\begin{array}{l}\text { D_1_Firmicutes;D_2_Bacilli;D_3_Lactobacillales;D_4_Streptococcaceae;D_5_ } \\
\text { Streptococcus }\end{array}$ \\
\hline $\begin{array}{l}\text { ffd03765b364ad4cdc17eb } \\
\text { ef2611ab72 }\end{array}$ & $\begin{array}{l}\text { D_1_Actinobacteria;D_2_Actinobacteria;D_3__Bifidobacteriales; } \\
\text { D_4_Bifidobacteriaceae;D_5_Bifidobacterium }\end{array}$ \\
\hline
\end{tabular}

857 Supplemental Table 6: ASVs identified in both urine and fecal samples. There were 66

858 ASVs found in both urine and fecal samples of any dog. 
bioRxiv preprint doi: https://doi.org/10.1101/2021.12.20.472715; this version posted December $21,2021$. The copyright holder for this preprint (which was not certified by peer review) is the author/funder, who has granted bioRxiv a license to display the preprint in perpetuity. It is made available under aCC-BY 4.0 International license.

\begin{tabular}{|c|c|}
\hline $\begin{array}{l}\text { ASVs in both urine and fecal } \\
\text { samples by dog }\end{array}$ & Taxa \\
\hline \multicolumn{2}{|l|}{$\operatorname{Dog} 1$ - UC } \\
\hline f8cc743ae9448d9472ef8d3914262ccb & $\begin{array}{l}\text { D_1__Proteobacteria;D_2__Gammaproteobacteria;D_3_Enterobacteriales; } \\
\text { D_4_Enterobacteriaceae;D_5_Escherichia-Shigella }\end{array}$ \\
\hline \multicolumn{2}{|r|}{ 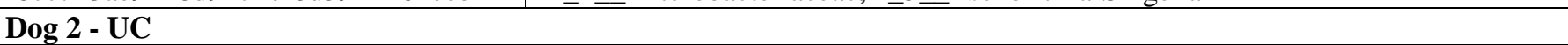 } \\
\hline 27046d59617e724675b68185aeb33d4a & $\begin{array}{l}\text { D_1__Firmicutes;D_2_Bacilli;D_3_Lactobacillales;D_4_Streptococcaceae; } \\
\text { D_5__Streptococcus }\end{array}$ \\
\hline \multicolumn{2}{|l|}{ Dog 3 - Healthy } \\
\hline f8cc743ae9448d9472ef8d3914262ccb & $\begin{array}{l}\text { D_1__Proteobacteria;D_2__Gammaproteobacteria;D_3_Enterobacteriales; } \\
\text { D_4_Enterobacteriaceae;D_5_Escherichia-Shigella }\end{array}$ \\
\hline 1878459013 cf15f2993a81c14978c980 & $\begin{array}{l}\text { D_1_Firmicutes;D_2_Bacilli;D_3_Lactobacillales;D_4_Streptococcaceae; } \\
\text { D_5_Streptococcus }\end{array}$ \\
\hline a3000823e9ab005bb353ff4e1e20eed8 & $\begin{array}{l}\text { D_1_Firmicutes;D_2_Clostridia;D_3_Clostridiales;D_4_Clostridiales } \\
1 ; D_{-} 5 \_ \text {Clostridium sensu stricto } 1\end{array}$ \\
\hline 601426df62ac2005c0a78bbe617425a4 & $\begin{array}{l}\text { D_1_Actinobacteria;D_2_Actinobacteria;D_3_Actinomycetales; } \\
\text { D_4_Actinomyceteaceae;D_5_Actinomyces;D_6_Actinomyces coleocanis }\end{array}$ \\
\hline $1905 \mathrm{e} 47315 \mathrm{e} 57 \mathrm{ce} 205 \mathrm{~d} 4505 \mathrm{f} 1 \mathrm{a} 5 \mathrm{c} 5 \mathrm{~d} 67$ & $\begin{array}{l}\text { D_1__Firmicutes;D_2_Bacilli;D_3_Lactobacillales;D_4_Streptococcaceae; } \\
\text { D_5_Streptococcus;D_6_Streptococcus minor }\end{array}$ \\
\hline \multicolumn{2}{|l|}{ Dog 4 - Healthy } \\
\hline 730125adfc6eae51053161e4a29f2bc9 & $\begin{array}{l}\text { D_1__Firmicutes;D_2_Bacilli;D_3_Lactobacillales;D_4_Enterococcaceae; } \\
\text { D_5_Enterococcus }\end{array}$ \\
\hline 35815582b2cf31eb986673cddccb558c & $\begin{array}{l}\text { D_1__Firmicutes;D_2_Clostridia;D_3_Clostridiales; } \\
\text { D_4_Peptostreptococcaceae; D_5_Peptoclostridium;D_6_uncultured bacterium }\end{array}$ \\
\hline
\end{tabular}

\section{Supplemental Table 7: ASVs in urine and fecal samples from the same dog. Four dogs}

863 contained ASVs that were found in both their urine and fecal samples. 
bioRxiv preprint doi: $\mathrm{https}$ //doi.org/10.1101/2021.12.20.472715: this version posted December 21, 2021. The copyright holder for this preprint (which was not certified by peer review) is the author/funder, who has granted bioRxiv a license to display the preprint in perpetuity. It is made available under aCC-BY 4.0 International license.

a

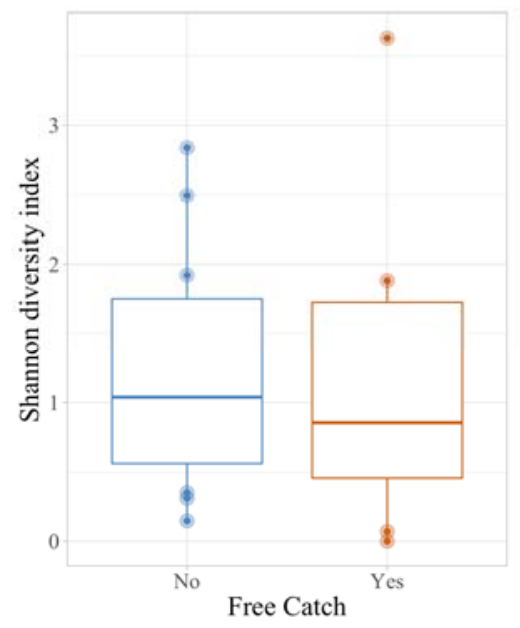

C

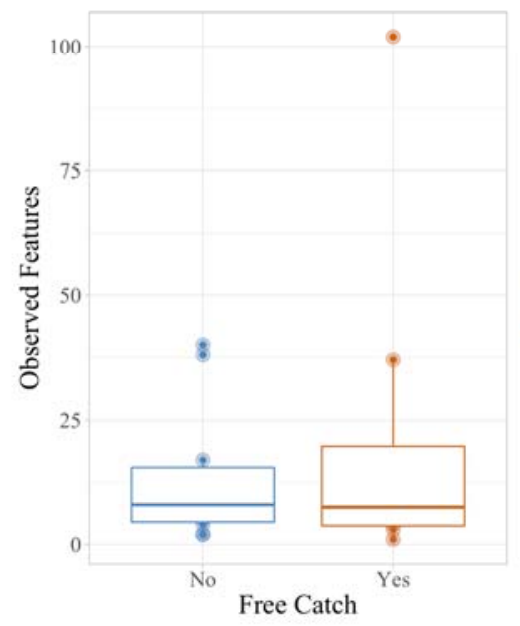

e

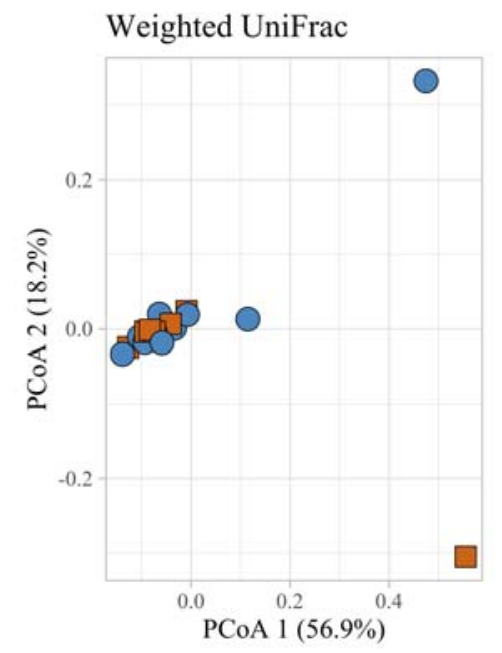

b

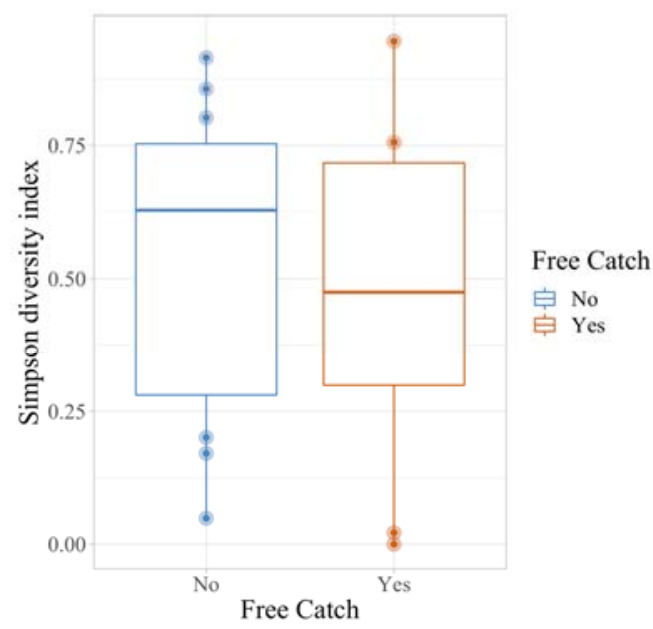

d

Unweighted UniFrac

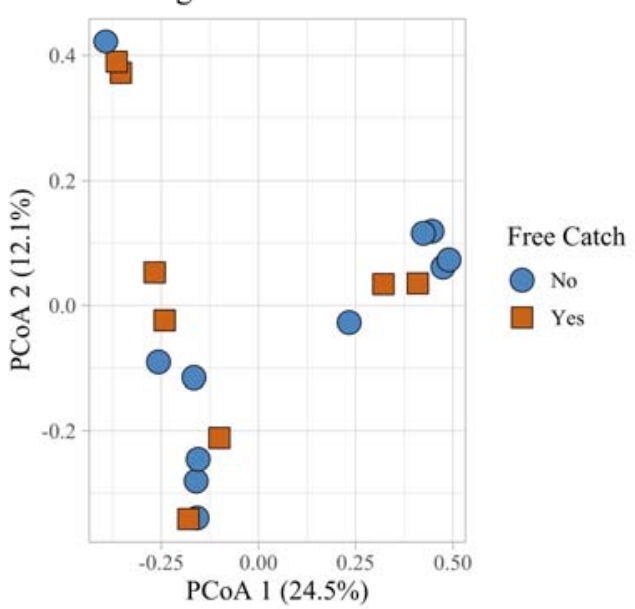

f

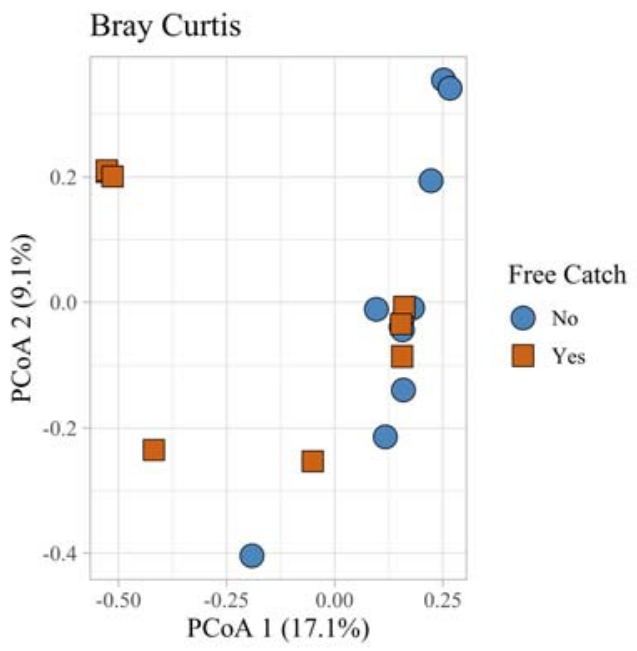

Free Catch

No

$\square$ Yes

官 No

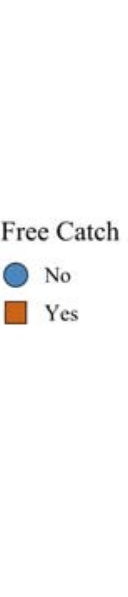




\section{Supplemental Figure 1: Urine microbial community diversity and composition by}

869 collection method in dogs with UC (rarefied data). Dogs with UC were sampled via free catch

$870(\mathrm{n}=8)$ and non-free catch $(\mathrm{n}=11)$ methods. Samples were rarefied at 1000 reads. There were no

871 significant differences in microbial diversity between collection methods as assessed via (a)

872 Shannon (Kruskal-Wallis: $p=0.62)$ or b) Simpson diversity indices $(p=0.68)$ or $(\mathbf{c})$ Observed

873 Features (richness) $(p=0.901)$. The microbial composition of free-catch urine did not differ

874 significantly from non-free catch urine based on (d) Unweighted (PERMANOVA, $p=0.328$ ) or

875 (e) Weighted UniFrac distance matrices $(p=0.485)$ but did differ significantly based on (f) Bray

876 Curtis $(p=0.008)$. Error bars denote standard error. 
bioRxiv preprint doi: https://doi.org/10.1101/2021.12.20.472715; this version posted December 21, 2021. The copyright holder for this preprint (which was not certified by peer review) is the author/funder, who has granted bioRxiv a license to display the preprint in perpetuity. It is made available under aCC-BY 4.0 International license.

a

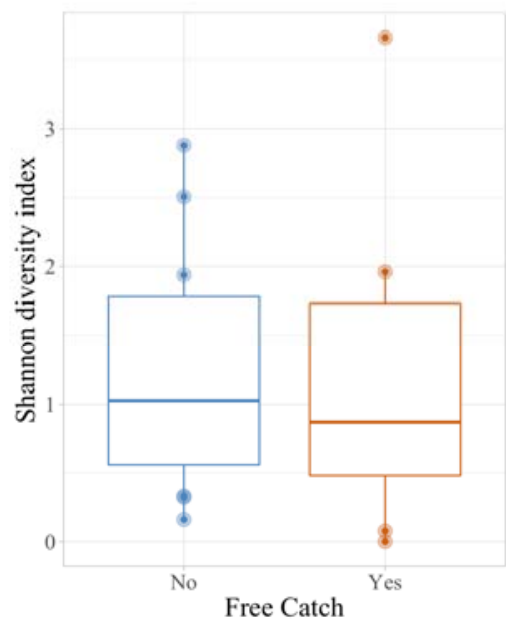

C

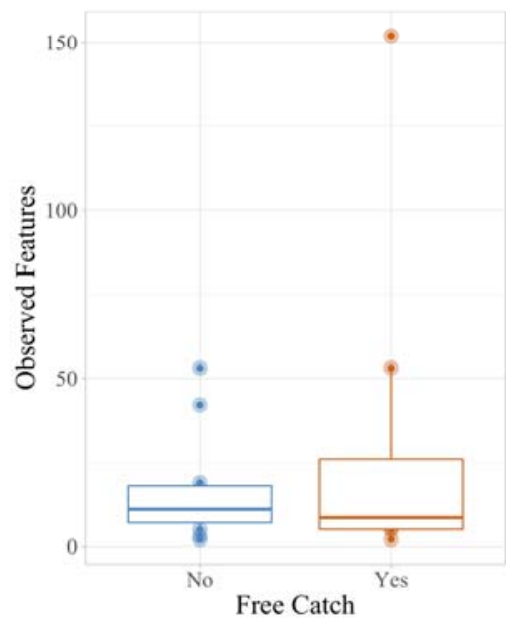

e

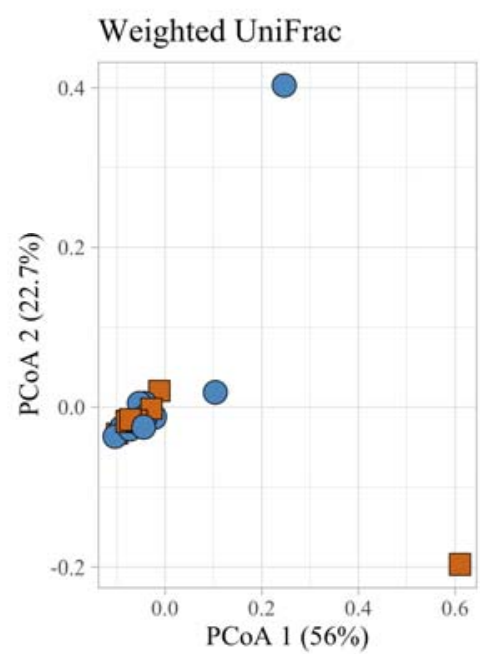

b

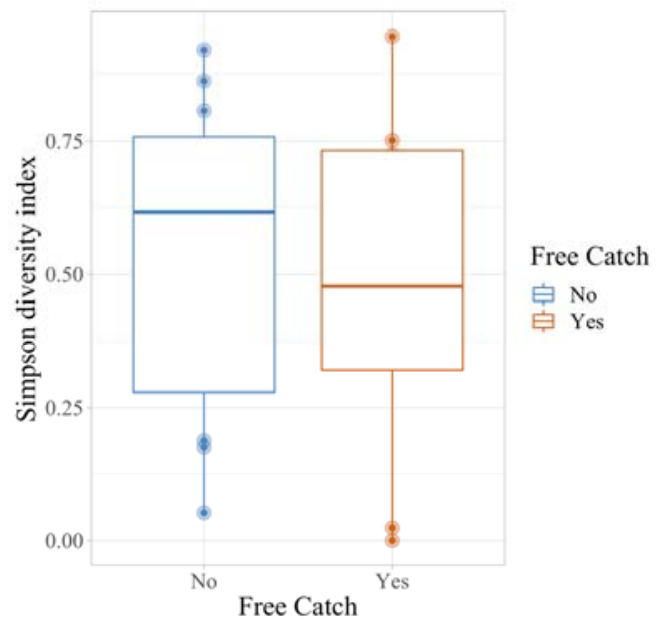

d

Unweighted UniFrac

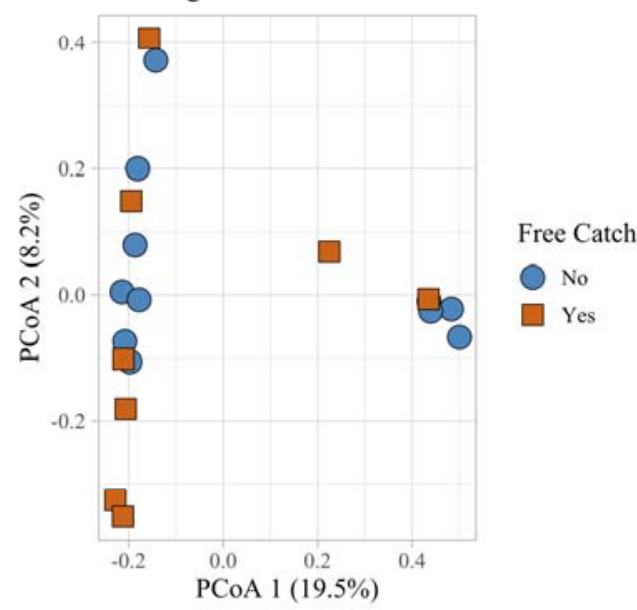

f

Bray Curtis

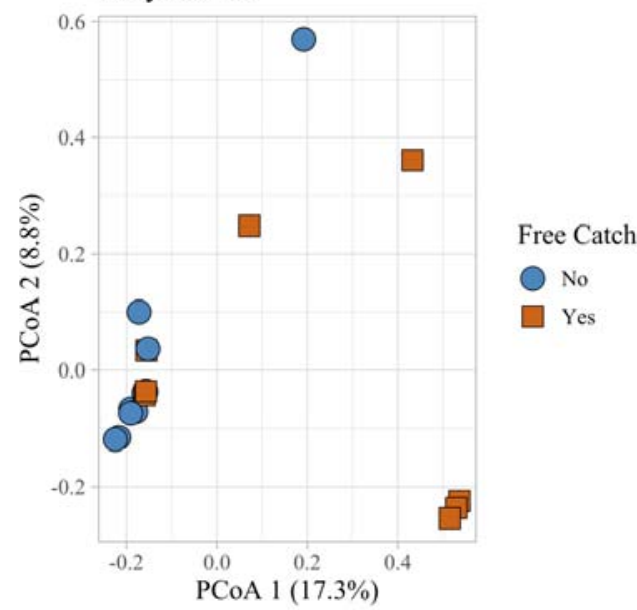

Free Catch

No

$\square$ Yes

Free Catch

皇 No

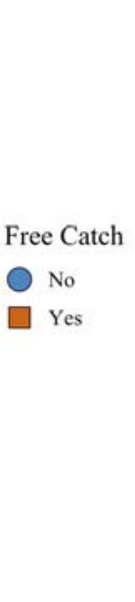




\section{Supplemental Figure 2: Urine microbial community diversity and composition by}

893 collection method in dogs with UC (unrarefied data). Dogs with UC were sampled via free

894 catch $(\mathrm{n}=8)$ and non-free catch $(\mathrm{n}=11)$ methods. Data are non-rarefied. There were no

895 significant differences in alpha diversity between collection methods as assessed using the (a)

896 Shannon (Kruskal-Wallis: $p=0.68)$ or b) Simpson diversity indices $(p=0.68)$ or $(\mathbf{c})$ Observed

897 Features (richness) $(p=0.901)$. The microbial composition of free-catch urine did not differ

898 significantly from non-free catch urine based on (d) Unweighted (PERMANOVA, $p=0.342$ ) or

899 (e) Weighted UniFrac distance matrices $(p=0.54)$ but did differ significantly based on (f) Bray

900 Curtis $(p=0.005)$. Error bars denote standard error.

901

902

903

904

905

906

907

908

909

910

911

912

913

914 
a

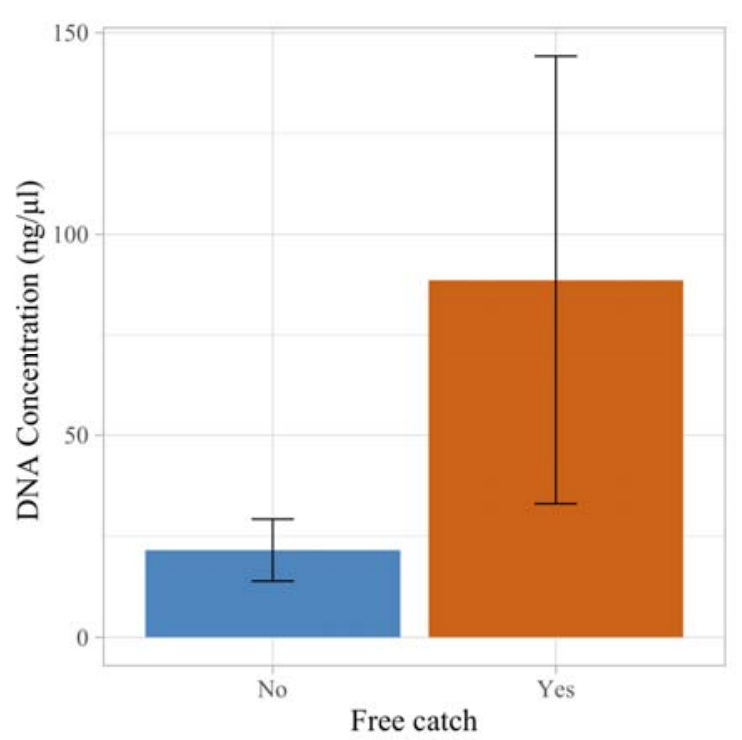

b

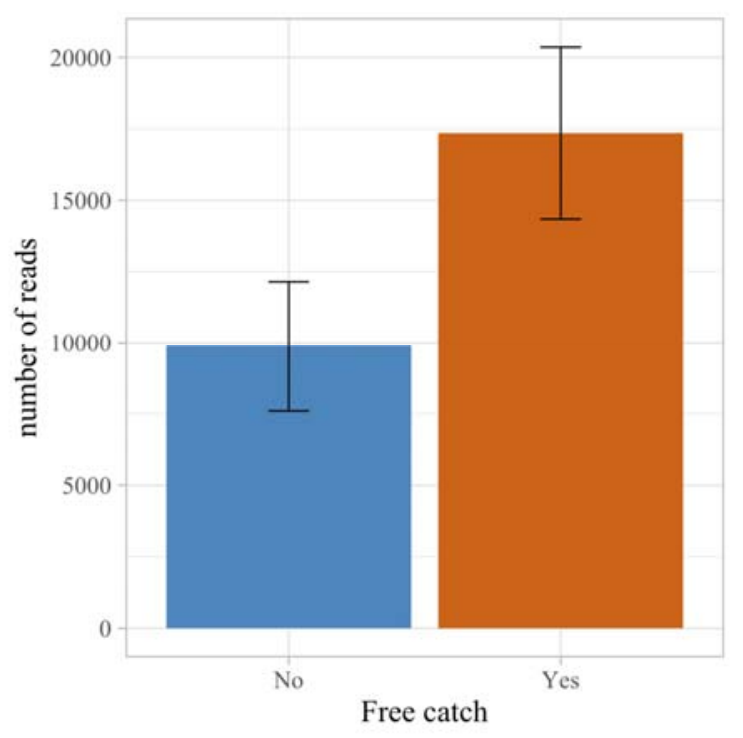

916 Supplemental Figure 3: DNA Concentrations and 16S reads by urine collection method. (a)

917 Urine DNA concentrations and (b) 16S reads in dogs with UC sampled via free catch or non-free

918 catch methods (cystoscopy, catheterization). DNA concentrations and 16S reads were greater,

919 although not significantly, in mid-stream free catch urine samples (DNA concentration:

920 Wilcoxon Test, $p=0.778 ; 16 \mathrm{~S}$ reads: two-sample t-test, $p=0.067)$. Error bars denote standard

921 error.

922

923

924

925

926

927

928

929 


\section{a}

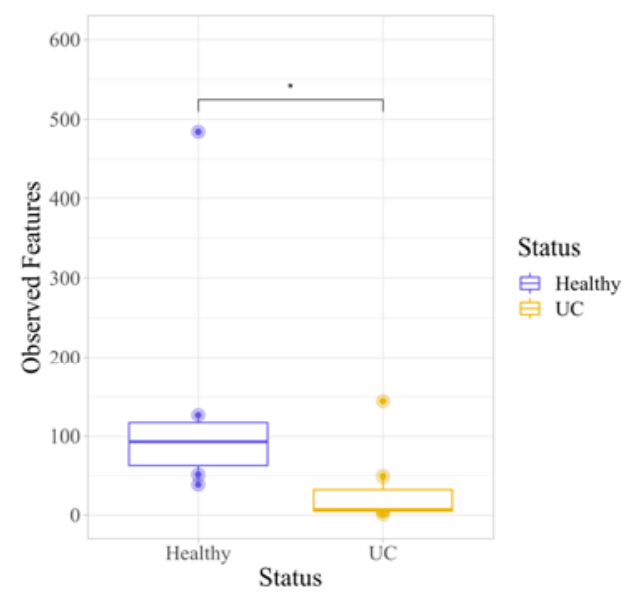

C

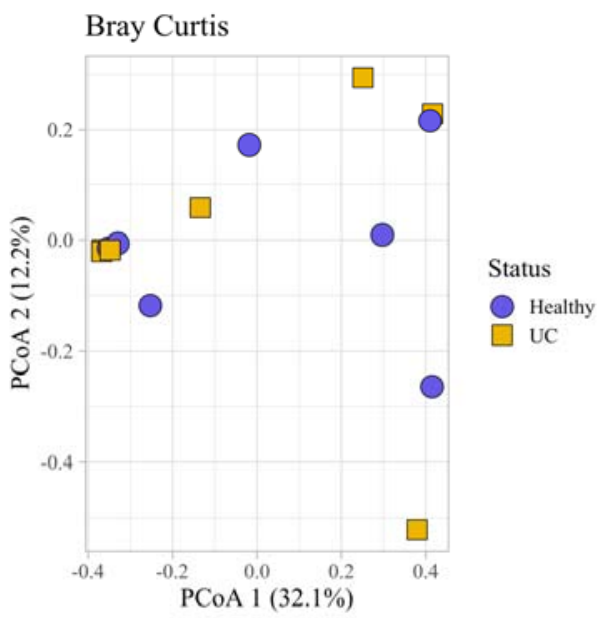

b
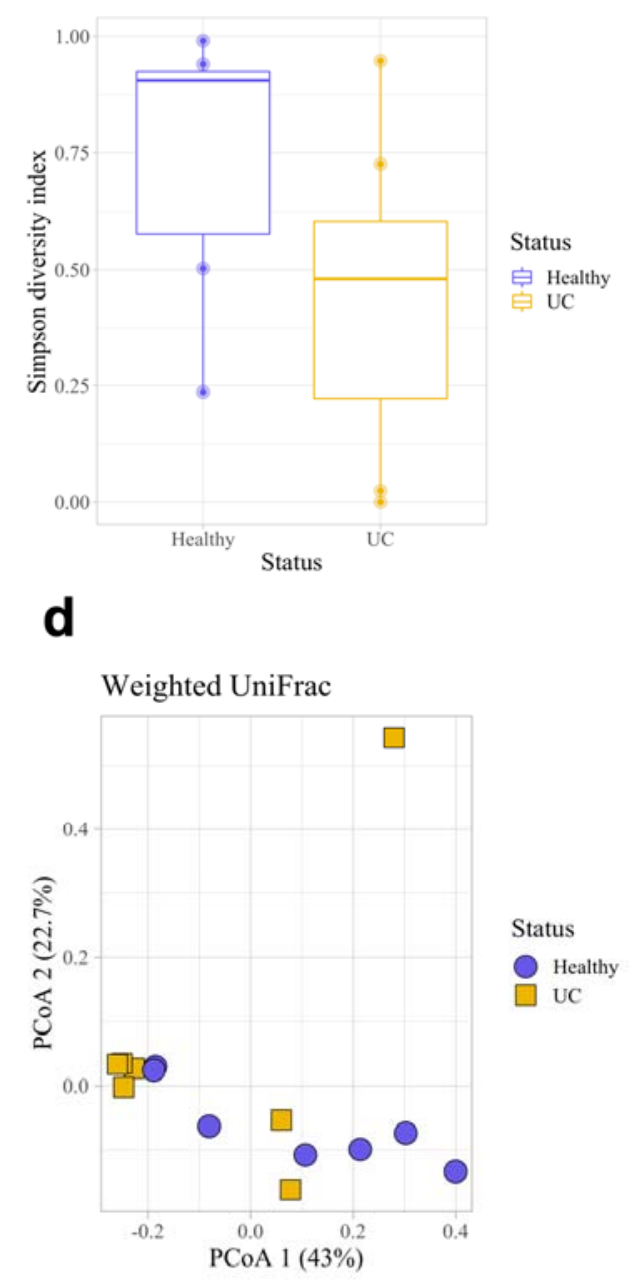

Supplemental Figure 4: Urine microbial diversity and composition in dogs with and

932 without UC. Dogs with UC had lower microbial diversity compared to healthy dogs based on

933 (a) Observed Features (richness) and the (b) Simpson diversity index; however, only Observed

934 Features was statistically significant (Kruskal-Wallis: Observed Features, $p=0.025$; Simpson, $p$

$935=0.133)$. Microbial composition did not differ significantly based on (c) Bray Curtis or (d)

936 Weighted UniFrac distance matrices (PERMANOVA: Bray Curtis, $p=0.888$; Weighted

937 UniFrac, $p=0.168$ ). Error bars denote standard error. Statistical significance is represented by

938 stars: $*<0.05, * *<0.001, * * *<0.0001$ 


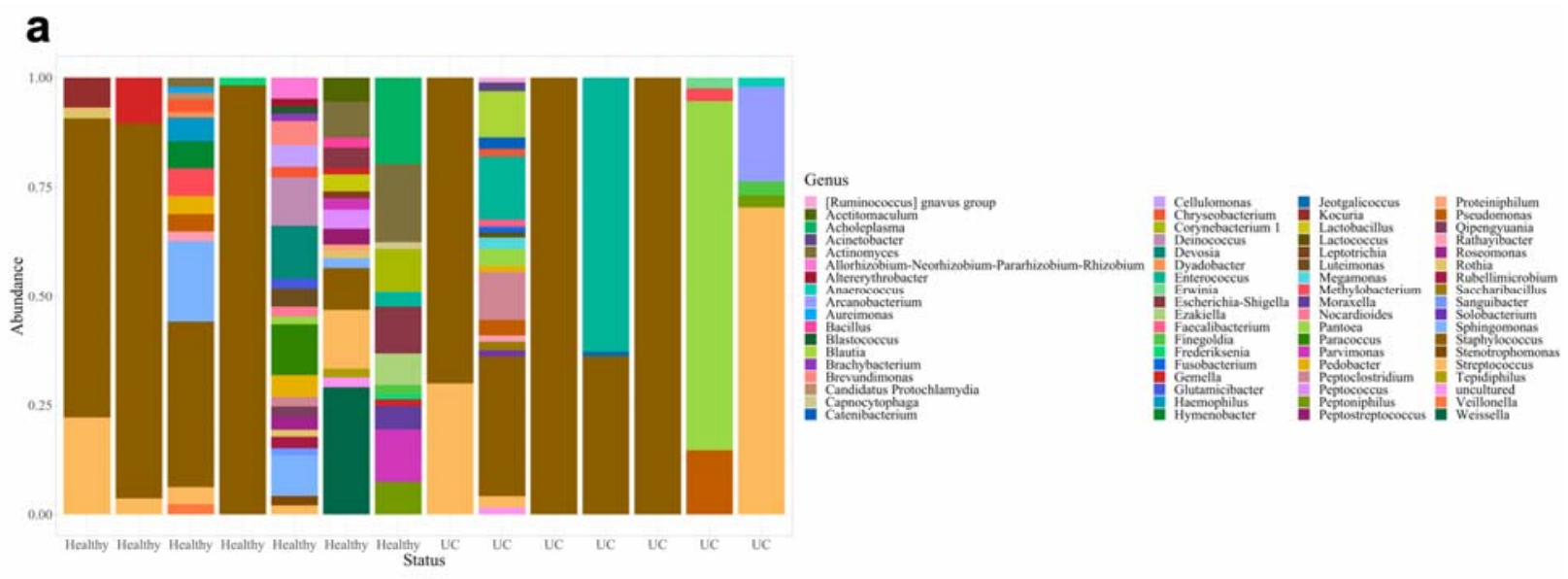

b

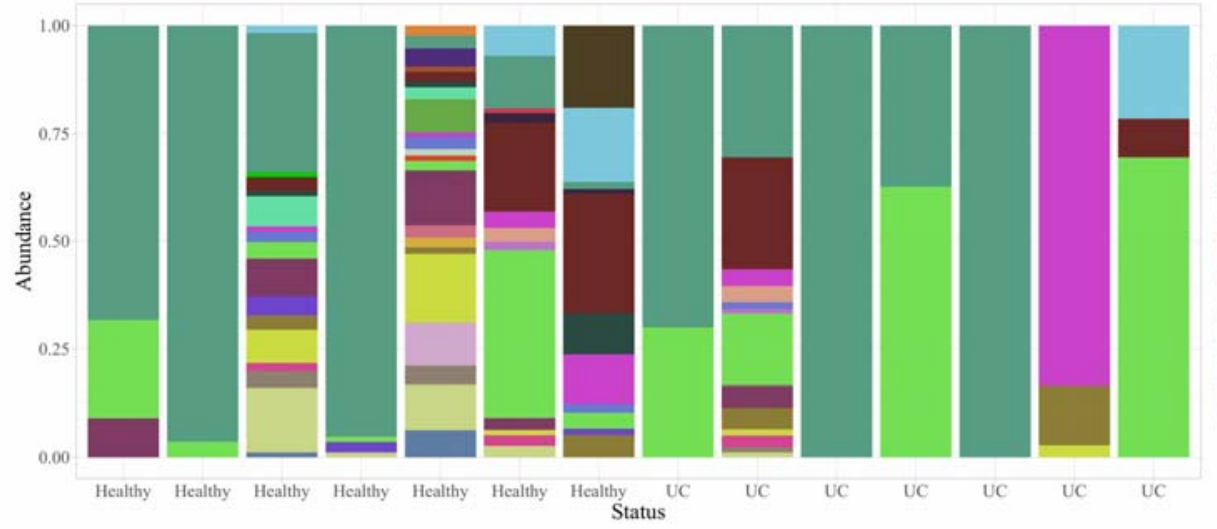
Order

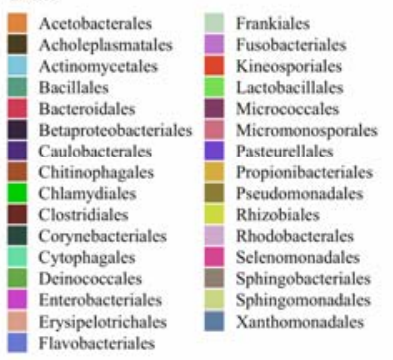

940 Supplemental Figure 5: Taxa bar plots of urine samples in dogs with and without UC. (a)

941 Microbial genera and (b) order relative abundances. 
a

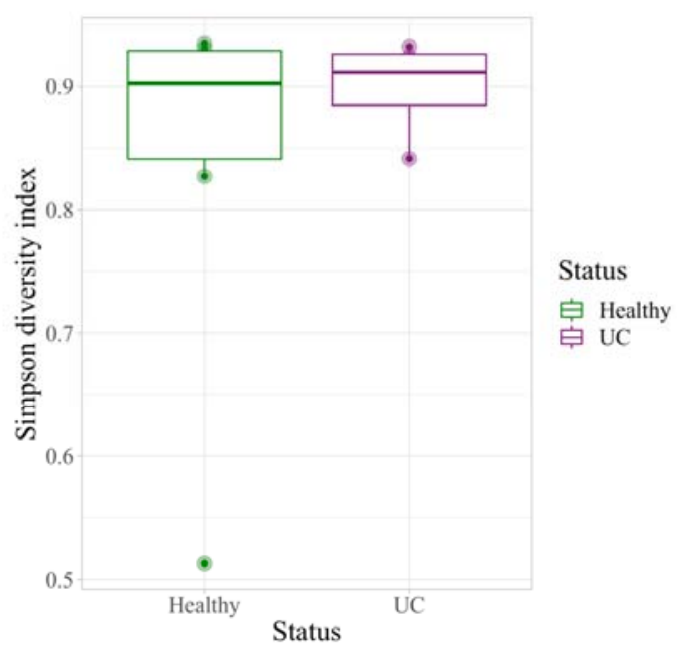

C

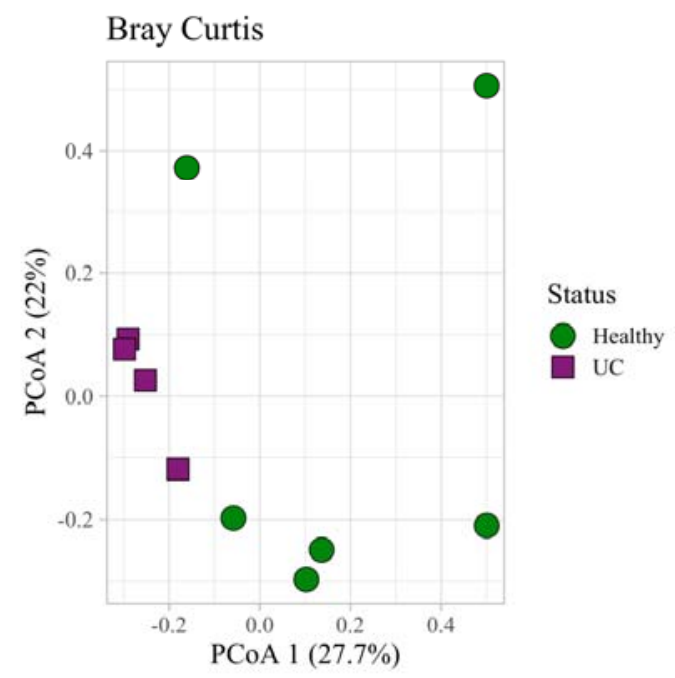

b
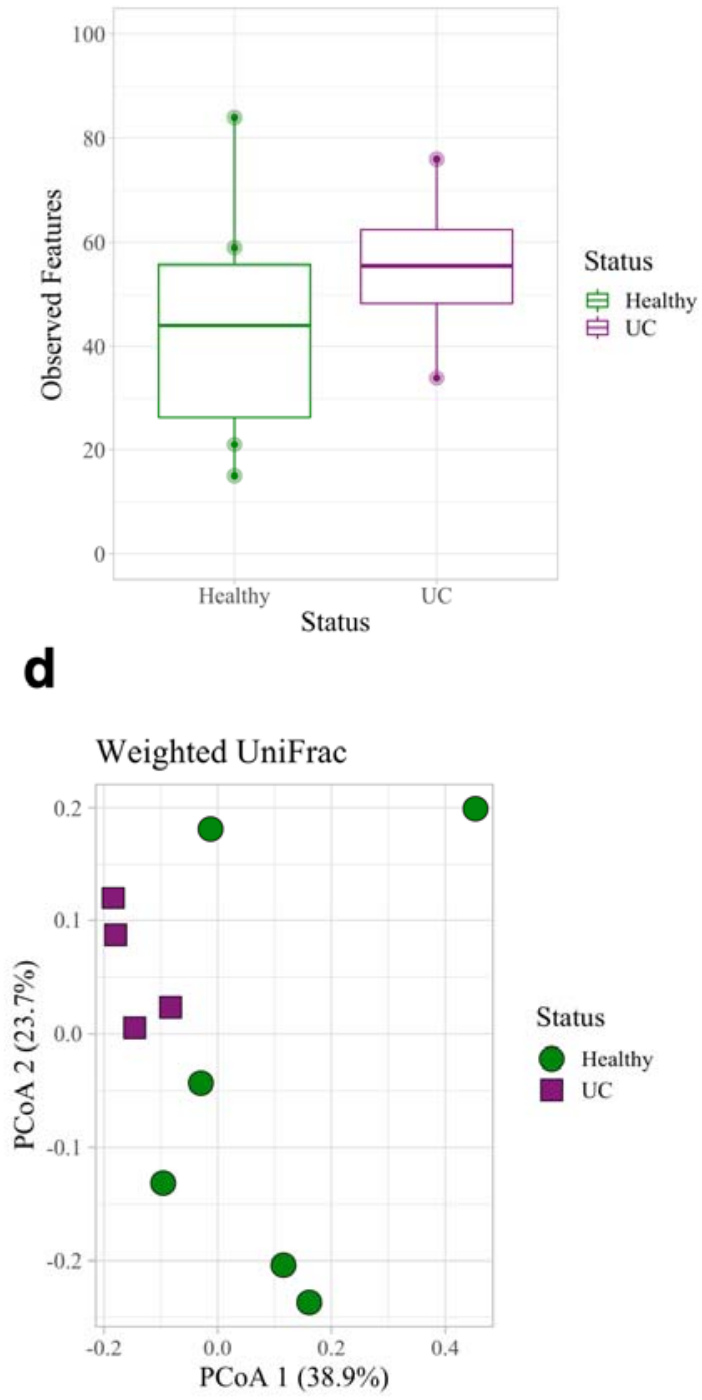

949 Supplemental Figure 6: Fecal microbial diversity and composition in dogs with and

950 without UC. Fecal microbial diversity did not differ significantly in dogs with $(n=4)$ or without

951 ( $\mathrm{n}=6)$ UC based on (a) Observed Features (richness) and the (b) Simpson diversity index

952 (Kruskal-Wallis: Observed Features, $p=0.67$; Simpson, $p=0.522$ ). Microbial composition also

953 did not differ significantly based on (c) Bray Curtis or (d) Weighted UniFrac distance matrices

954 (PERMANOVA: Bray Curtis, $p=0.06$; Weighted UniFrac, $p=0.06$ ). Error bars denote standard

955 error. 
bioRxiv preprint doi: https://doi.org/10.1101/2021.12.20.472715; this version posted December 21, 2021. The copyright holder for this preprint (which was not certified by peer review) is the author/funder, who has granted bioRxiv a license to display the preprint in perpetuity. It is made available under aCC-BY 4.0 International license.

a

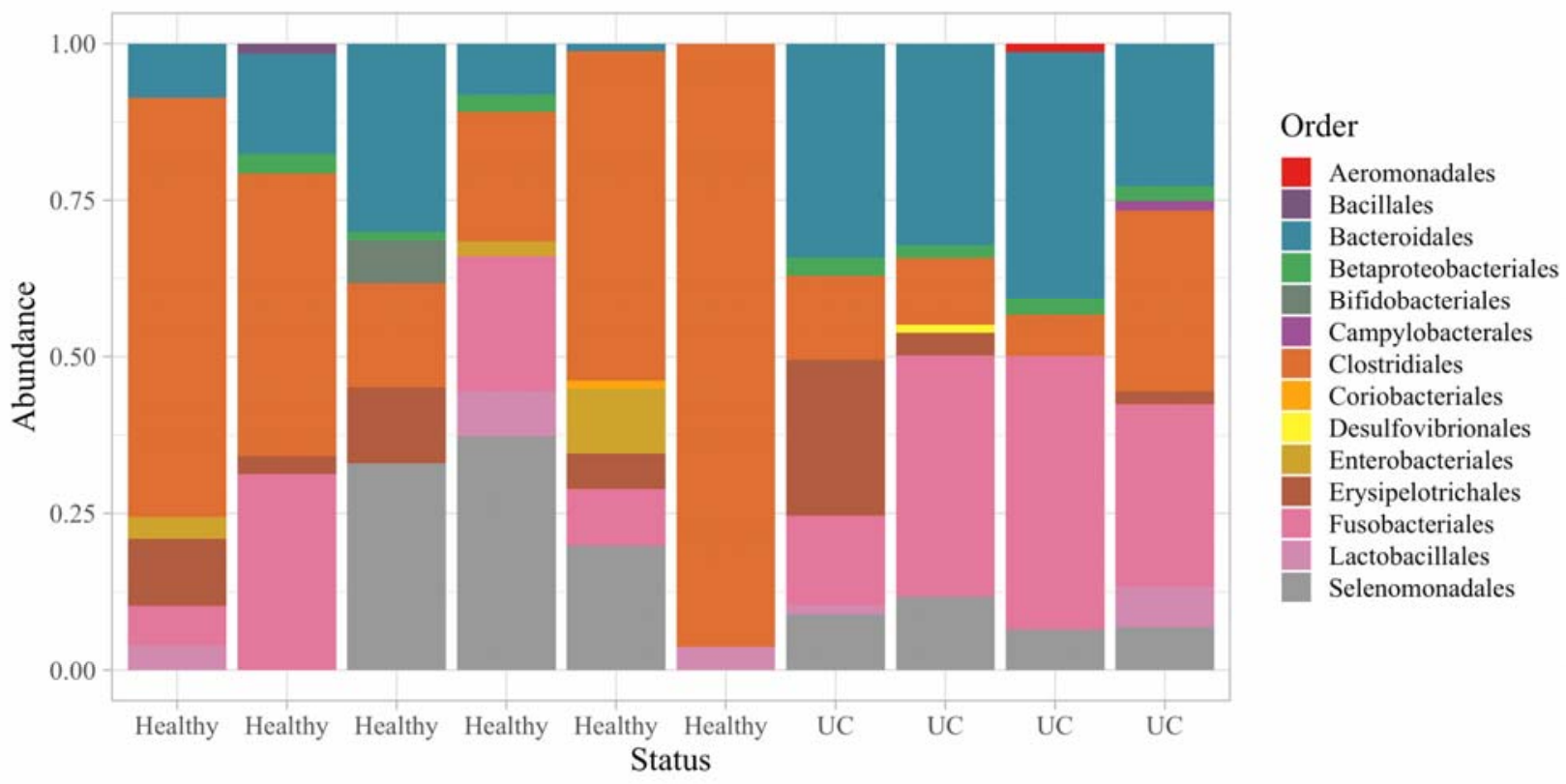

b

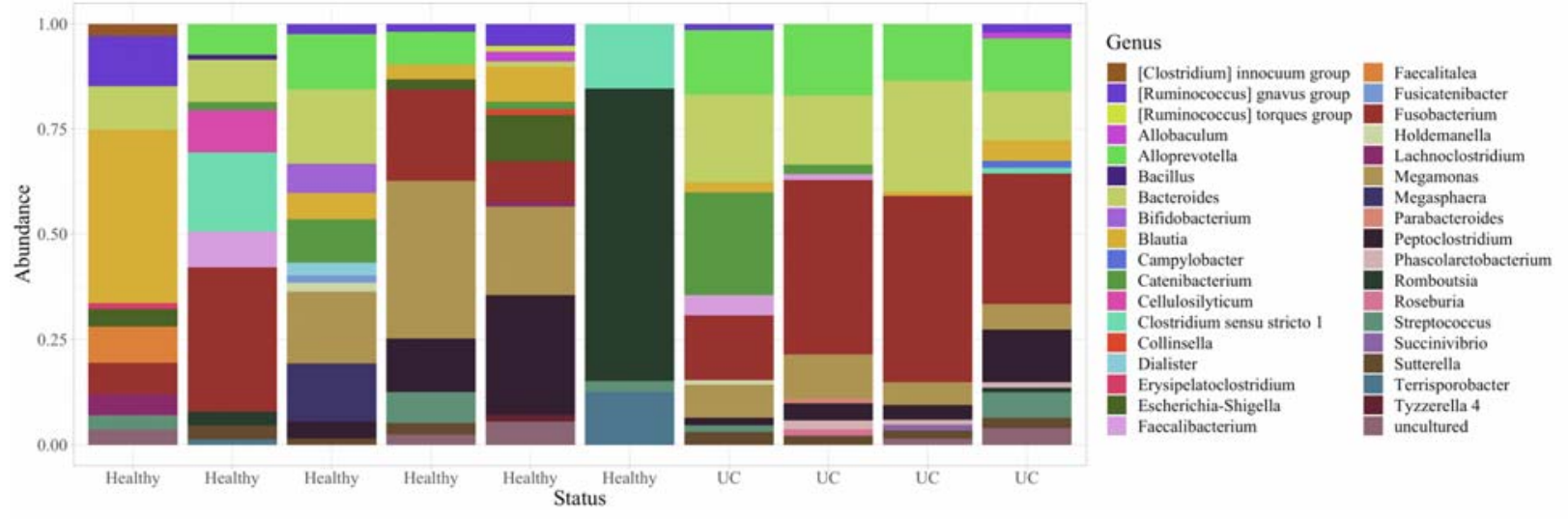

957 Supplemental Figure 7: Taxa bar plots of fecal samples. (a) Microbial order and (b) genera

958 relative abundances in dogs with $(n=4)$ and without $\mathrm{UC}(\mathrm{n}=6)$. 
bioRxiv preprint doi: $\mathrm{https}$ ///doi.org/10.1101/2021.12.20.472715 this version posted December 21, 2021. The copyright holder for this preprint (which was not certified by peer review) is the author/funder, who has granted bioRxiv a license to display the preprint in perpetuity. It is made available under aCC-BY 4.0 International license.

a

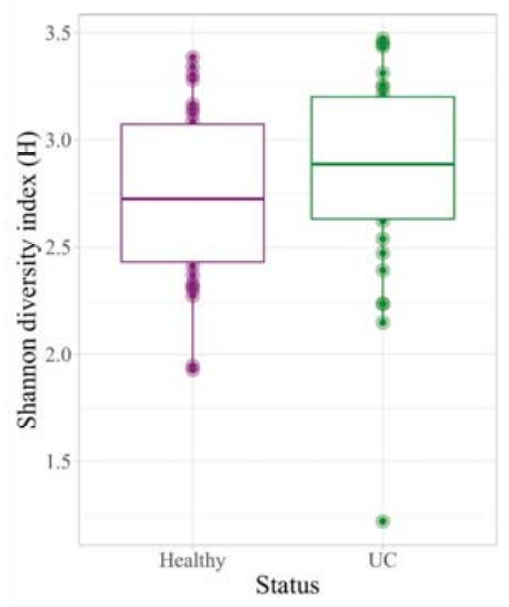

C

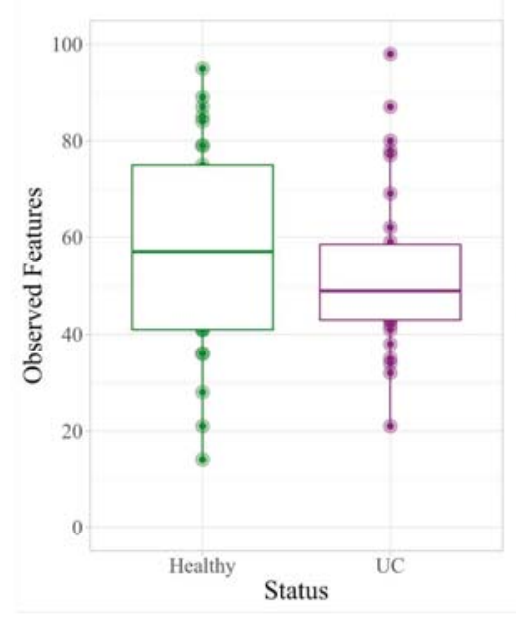

e

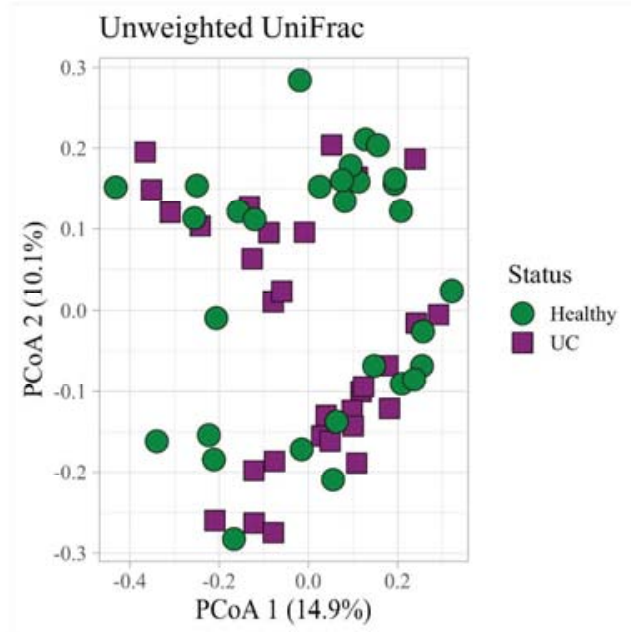

b

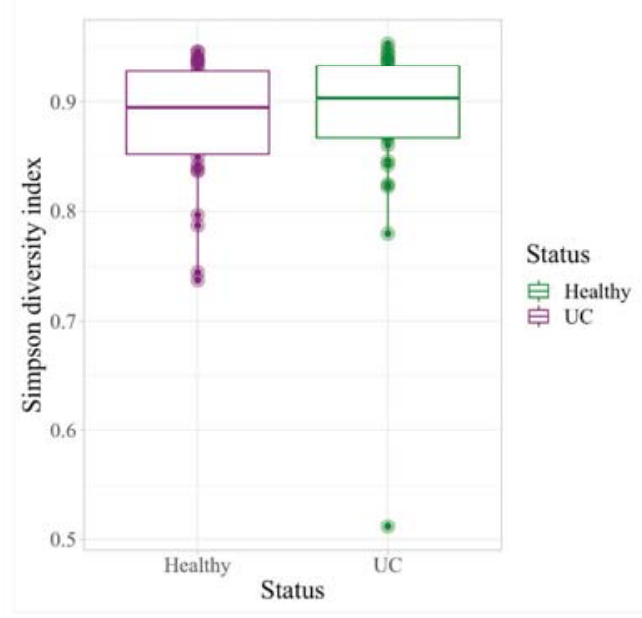

d

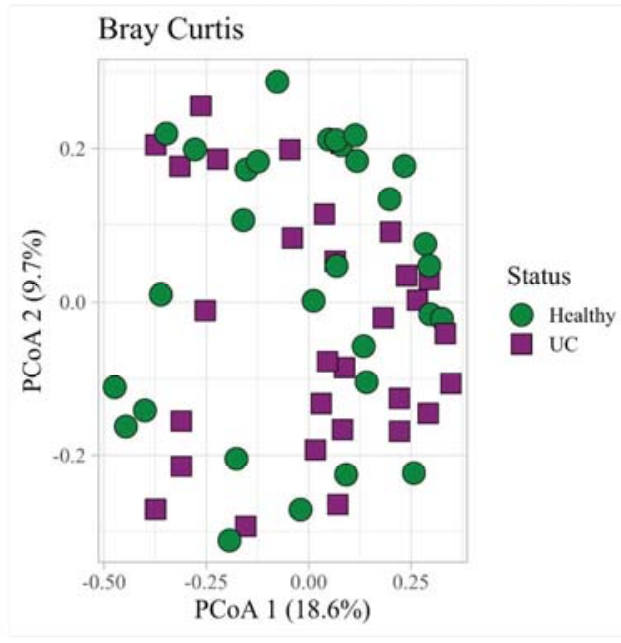

f

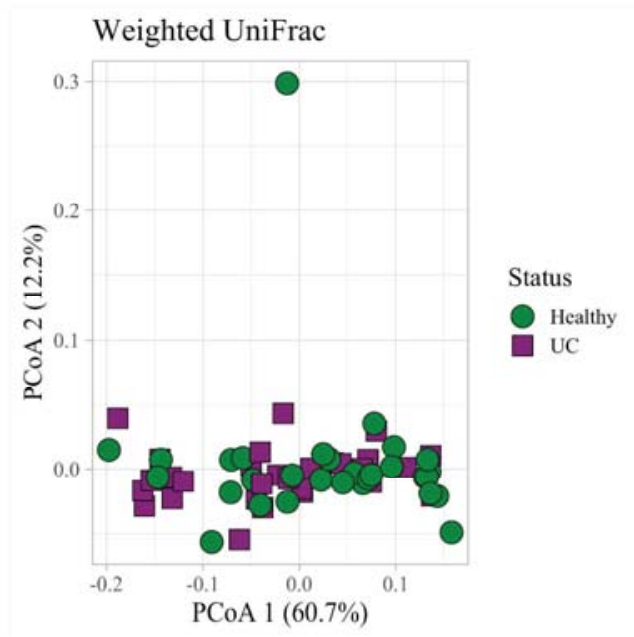


965 Supplemental Figure 8: Fecal microbial diversity and composition. We compared fecal

966 microbiota in dogs with UC $(\mathrm{n}=30)$ and sex-, age-, and breed-matched healthy controls $(\mathrm{n}=$

967 30). There were no significant differences in microbial diversity by (a) Shannon (Kruskal-Wallis,

$968 p=0.214$ ), (b) Simpson (Kruskal-Wallis, $p=0.506$ ), or (c) Observed Features (Kruskal-Wallis,

$969 p=0.336)$. There were also no significant differences in microbial composition by (d) Bray

970 Curtis (PERMANOVA, $p=0.468)$, (e) Unweighted UniFrac (PERMANOVA, $p=0.134)$, or (f)

971 Weighted UniFrac distance matrices (PERMANOVA, $p=0.0819$ ). 
bioRxiv preprint doi: https://doi.org/10.1101/2021.12.20.472715; this version posted December 21, 2021. The copyright holder for this preprint (which was not certified by peer review) is the author/funder, who has granted bioRxiv a license to display the preprint in perpetuity. It is made available under aCC-BY 4.0 International license.

a

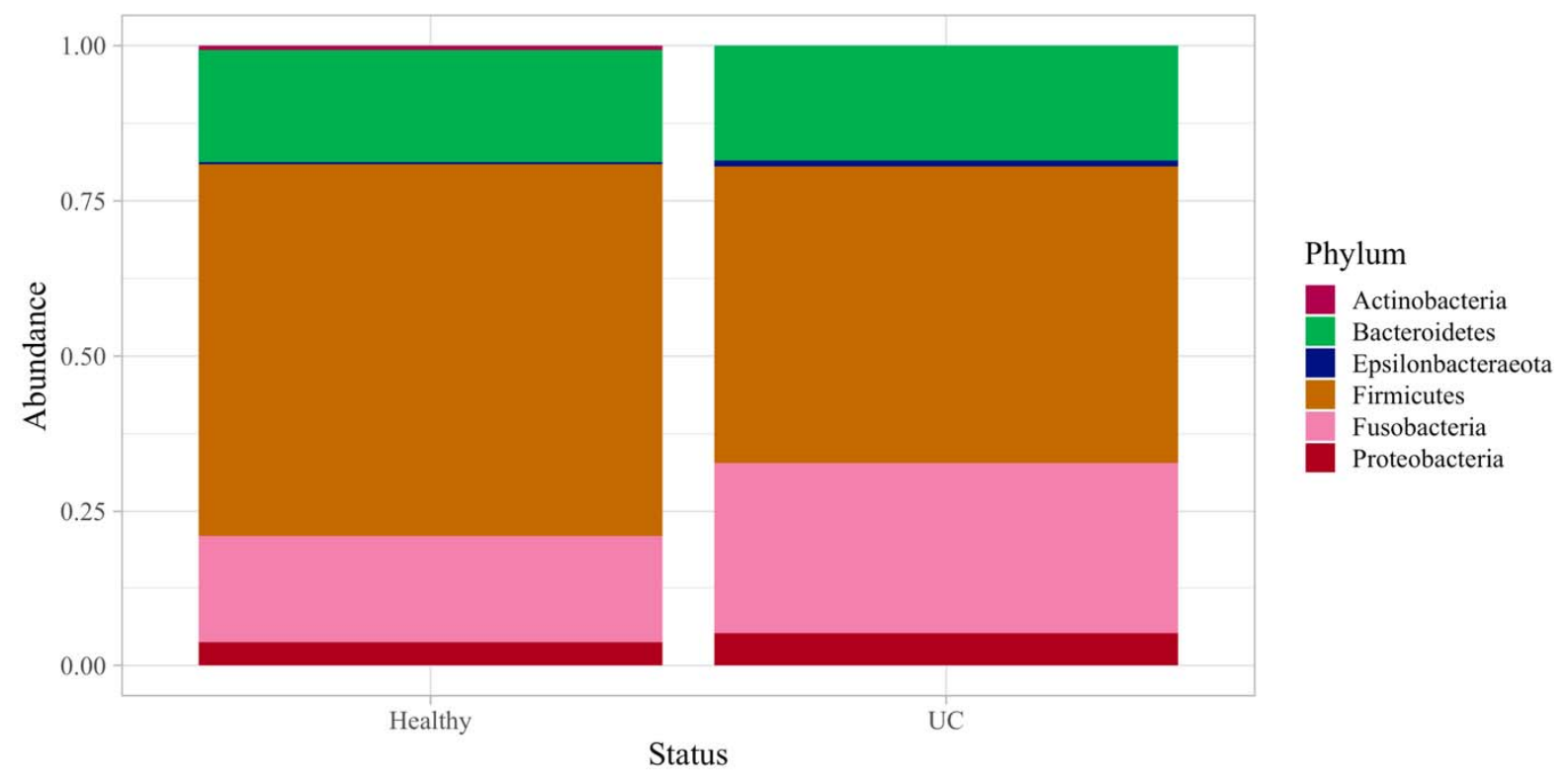

b

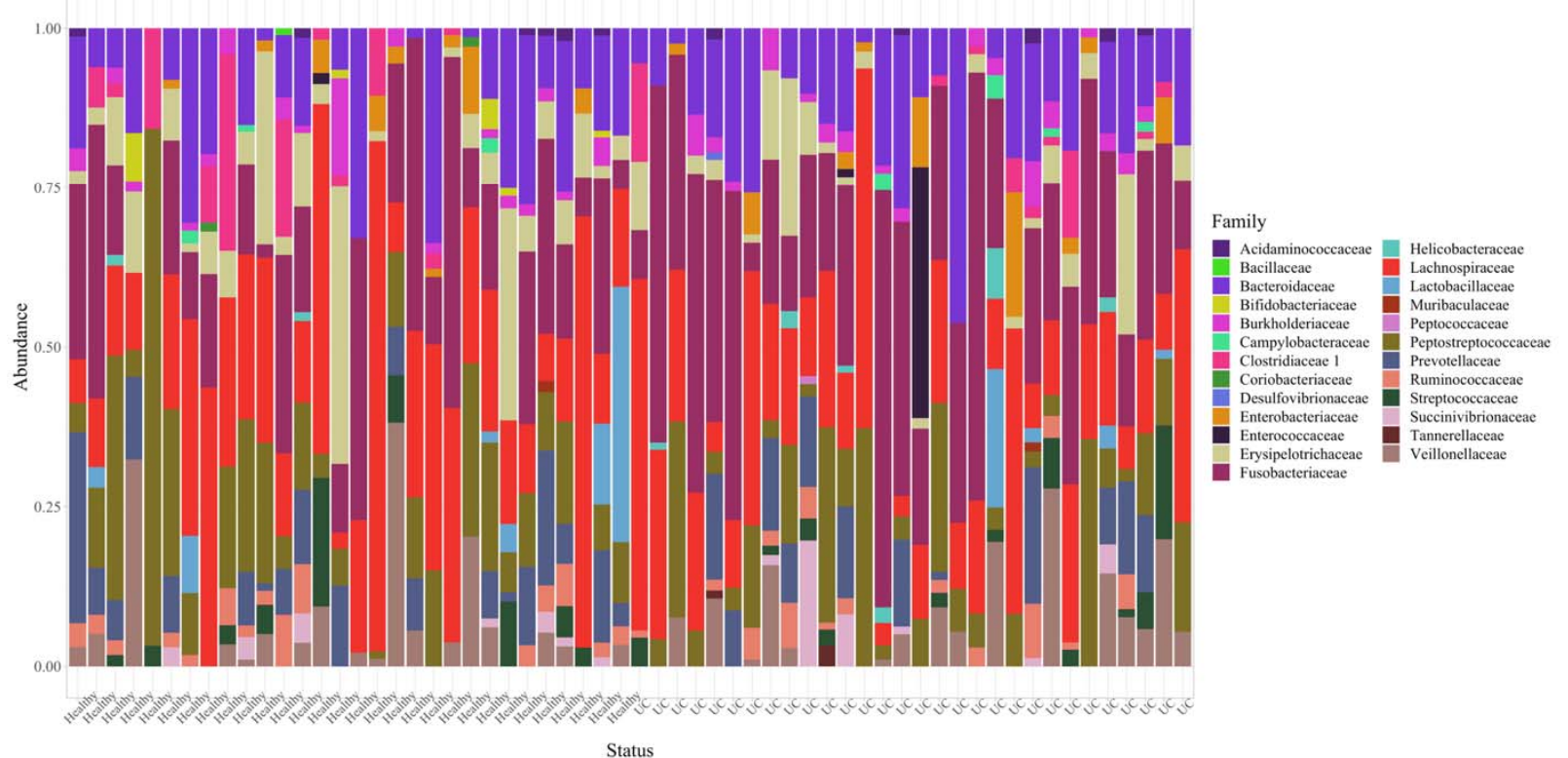

974 Supplemental Figure 9: Fecal microbial taxa bar plots. Relative abundances of fecal

975 microbiota at the (a) phyla and (b) family levels from dogs with UC (n=30) and age-, sex-, and

976 breed-matched healthy controls $(\mathrm{n}=30)$. 